\title{
C3G MEDIATED SUPPRESSION OF MALIGNANT TRANSFORMATION \\ INVOLVES ACTIVATION OF PP2A PHOSPHATASES AT THE SUBCORTICAL ACTIN CYTOSKELETON
}

\author{
Susana Martín-Encabo, Eugenio Santos and Carmen Guerrero \\ From Centro de Investigación del Cáncer, IBMCC, Universidad de Salamanca-CSIC, 37007- \\ Salamanca, Spain.
}

Running title: PP2A mediates C3G transformation suppression

Key words: C3G; PP2A; ERK; actin cytoskeleton; transformation suppression

Address correspondence to:

Carmen Guerrero

Tel: 34923294801

Fax: 34923294795

e-mail: cguerrero@usal.es) or

Eugenio Santos

Tel: 34923294720

Fax: 34923294743

e-mail: esantos@usal.es) 


\section{Abstract}

In previous work, we demonstrated that $\mathrm{C} 3 \mathrm{G}$ suppresses Ras oncogenic transformation by a mechanism involving inhibition of ERK phosphorylation. Here we present evidences indicating that this suppression mechanism is mediated, at least in part, by serine/threonine phosphatases of the PP2A family. Thus: (i) ectopic expression of $\mathrm{C} 3 \mathrm{G}$ or $\mathrm{C} 3 \mathrm{G} \Delta \mathrm{Cat}$ (mutant lacking the GEF activity) increases specific ERK-associated PP2A phosphatase activities; (ii) C3G and PP2A interact, as demonstrated by immunofluorescence and co-immunoprecipitation experiments; (iii) association between PP2A and MEK or ERK increases in C3G overexpressing cells; (iv) phosphorylated-inactive PP2A level decreases in C3G expressing clones and, most importantly, (v) okadaic acid reverts the inhibitory effect of C3G on ERK phosphorylation. Moreover, C3G interacts with Ksr-1, a scaffold protein of the Ras-ERK pathway that also associates with PP2A. The fraction of C3G involved in transformation suppression is restricted to the subcortical actin cytoskeleton where it interacts with actin. Furthermore, the association between C3G and PP2A remains stable even after cytoskeleton disruption with cytochalasin $\mathrm{D}$, suggesting that the three proteins form a complex at this subcellular compartment. Finally, C3G- and C3G $\Delta$ Cat-mediated inhibition of ERK phosphorylation is reverted by incubation with cytochalasin D. We hypothesize that C3G triggers PP2A activation and binding to MEK and ERK at the subcortical actin cytoskeleton, thus favouring ERK dephosphorylation. 


\section{Introduction}

The $\mathrm{C} 3 \mathrm{G}$ gene product is a Crk-binding protein, acting as an exchange factor for the Rap and R-Ras proteins $[1,2]$, that plays a crucial role in integrin mediated cell adhesion and migration [3-7]. In several models Crk-C3G complexes participate in ERK activation via Ras- and/or Rap1-dependent mechanisms [8-11], but in others, such as Chinese hamster ovary (CHO) cells, there is an inverse correlation between the presence of a CrkII-C3G functional complex and the ERK activity, which suggests the involvement of C3G in an ERK suppression pathway [12]. In this lane, our laboratory has recently shown in NIH3T3 fibroblasts that C3G suppresses malignant transformation induced by several oncogenes by a process that is independent of its exchange activity but dependent on its SH3-binding domain. The mechanism of suppression of Hras $^{\text {Lys12 }}$-mediated oncogenic transformation involves inhibition of ERK/MAPK phosphorylation and cyclin A expression, which result in the loss of transformed cells capacity to growth in non-adherent conditions $[13,14]$. Our data demonstrated that $\mathrm{C} 3 \mathrm{G}$ acts at the level of ERK without affecting other steps in the Ras-ERK cascade, suggesting that $\mathrm{C} 3 \mathrm{G}$ could operate through the activation of cellular phosphatases. In fact, the activity of ERK/MAPK depends on the equilibrium between the activities of the upstream kinases and protein phosphatases. Dephosphorylation of either the threonine or the tyrosine residue is sufficient for inactivation and this can be accomplished by tyrosine-specific phosphatases, serine/threonine phosphatases or by dual specificity (threonine/tyrosine) phosphatases $[15,16]$. The protein phosphatase 2A (PP2A) family comprises the major serine/threonine phosphatases involved in signal transduction and the regulation of growth and development $[17,18]$. PP2A family of phosphatases are heterotrimeric holoenzymes consisting of a core dimer composed of a scaffolding/structural (A) subunit and a catalytic (C) subunit. This dimer associates with a variety of regulatory (B) subunits. Thus far, four distinct families of regulatory subunits have 
been identified: B or PR55, B' or PR61 (also B56), B"' or PR72, and B"' or PR93/PR110 [18, 19].

Immunoprecipitation studies have revealed that PP2A associates with ERK and MEK [20] as well as with the kinase suppressor of Ras 1 (Ksr-1) [21] and Raf1 [22]. In fact, PP2A phosphatases participate in both positive and negative regulation of ERK/MAPK signaling pathway at multiple entry points $[21,23-26]$ depending on the cell type, its subcellular localization [18] and the holoenzyme composition, being the regulatory B subunits the responsible of the specificity $[24,27]$.

Although $\mathrm{C} 3 \mathrm{G}$ in its inactive state shows a cytoplasmic, perinuclear location [13], phosphorylated-activated $\mathrm{C} 3 \mathrm{G}$ localizes specifically to the subcortical actin cytoskeleton and Golgi apparatus [28], suggesting a possible function for $\mathrm{C} 3 \mathrm{G}$ at these subcellular compartments. In fact, phosphorylation of $\mathrm{C} 3 \mathrm{G}$ results in an increase in $\mathrm{C} 3 \mathrm{G}$ catalytic activity towards its substrate Rap1, which localizes mainly to the Golgi and lysosomal vesicles [29]. Nevertheless, the location of the Rap1-independent C3G suppressor activity has not been established.

Here we show a novel function of $\mathrm{C} 3 \mathrm{G}$ as phosphatase activator. Furthermore, the inhibitory effect of $\mathrm{C} 3 \mathrm{G}$ on ERK phosphorylation seems to be mediated by phospho-ERK specific PP2A phosphatases. In addition, the $\mathrm{C} 3 \mathrm{G}$ suppression function is located at the subcortical actin cytoskeleton, where $\mathrm{C} 3 \mathrm{G}$ and PP2A interact. We propose that C3G suppressor activity of Rasmediated transformation is located at the subcortical actin cytoskeleton and involves the inactivation of the Ras-ERK pathway at the level of ERK by specific PP2A holoenzymes. 


\section{Materials and methods}

\section{Cell Cultures}

In this work we used mass cultures of NIH3T3 cells stably transfected with pLTR2, pLTR2C3G (containing the complete human C3G cDNA) or pLTR2C3G $\Delta$ Cat (a C3G mutant devoid of its catalytic domain but retaining the transformation suppression function) alone or in combination with pMEXneoHras ${ }^{\text {Lys12 }}[13,14]$. For simplification, we will refer to these constructs in the text as pLTR2, C3G, C3G $\Delta$ Cat and Hras ${ }^{\text {Lys12 }}$, respectively.

\section{Antibodies and organelle markers}

For immunoblotting and immunoprecipitation studies we used: anti-C3G (C-19), anti-C3G (H300), anti-Actin (C-11), anti-MEK1 (C-18), anti-ERK1 (K-23) and anti-Ksr-1 (C-19) from Santa Cruz Biotechnologies (Santa Cruz, CA, USA); anti-phospho-p44/42 MAP Kinase (Thr202/Tyr204) (anti-phospho-ERK1/2) and anti-phospho-MEK1/2 (Ser217/221) from Cell Signaling Technology, Inc. (Beverly, MA, USA); anti-PP2A, C subunit, clone 1D6 from Millipore-Upstate (Billerica, MA); anti-phospho-PP2A (Y307) from Epitomics, Inc. (Burlingame, CA, USA).

For immunofluorescence studies we used as primary antibodies: anti-PP2A, C subunit, clone 1D6 and anti-C3G 1008 [13]. As secondary antibodies we used: Cy3 anti-rabbit, FITC anti-mouse and $\mathrm{Cy} 3$ anti-mouse from Jackson ImmunoResearch Laboratories, Inc. (West

Grove, PA, USA). For detection of cytoplasmic organelles we used: Oregon Green ${ }^{\circledR} 514$ phalloidin from Invitrogen-Molecular Probes (Carlsbad, CA, USA) and anti-GM130 from BD Biosciences (San Jose, CA, USA). 


\section{Immunoblotting}

Whole cell lysates were prepared by extracting with Cell Lysis Buffer purchased from Cell Signaling Technology, Inc. (\#9803) or with RIPA buffer (20 mM Tris-HCl pH 7.5, $150 \mathrm{mM}$ $\mathrm{NaCl}, 1 \%$ Triton X-100 (or NP-40), $0.1 \% \mathrm{Na}$ deoxycholate, $0.1 \%$ SDS) supplemented with 1 mM PMSF, $10 \mu \mathrm{g} / \mathrm{ml}$ Aprotinin and $10 \mu \mathrm{g} / \mathrm{ml}$ Leupeptin. The cell debris was removed by spinning at $10,000 \mathrm{~g}$ for $10 \mathrm{~min}$ at $4{ }^{\circ} \mathrm{C}$.

\section{Immunoprecipitation}

Immunoprecipitation was performed essentially as described [30]. Briefly, $500 \mu \mathrm{g}$ of protein from whole cell lysates were incubated with the antibody for $2 \mathrm{~h}$. After this, GammaBind G Sepharose beads (Amersham Biosciences, Uppsala, Sweden) were added, and the incubation was continued for one more hour. The beads with the immunocomplexes were pelleted and washed with 1x Cell Lysis Buffer (see above) three times and either boiled with 1x sample buffer for immunoblotting or processed for kinase assay.

\section{Immunofluorescence}

Culture plates $(60 \mathrm{~mm})$ containing 2-3 coverslips were covered with $1 \mu \mathrm{g} / \mathrm{ml}$ poly-lysine (Sigma-Aldrich, Corp. St. Louis, MO, USA) during 15 min, water washed, dried under hood for $2 \mathrm{~h}$ and seeded with 30,000 cells/plate. After overnight growth and treatment with agonists and inhibitors, cells were washed twice with cold PBS and fixed with freshly prepared $3.7 \%$ formaldehyde during 15 min, washed again three more times in PBS and permeated with $0.1 \%$ Triton in PBS for additional 10 min. After blocking in 1\% BSA/PBS during 15 min cells were incubated with primary antibody, diluted in same blocking solution, for $1 \mathrm{~h}$ followed by incubation in the dark with fluorescent fluorochrome-labelled specific secondary antibody. Finally, after three washes in PBS, coverslips were mounted over the slides with Mowiol 4-40 
(Calbiochem, EMD Biosciences, San Diego, CA, USA) or, in the case of organelle staining, incubated with the specific marker and then mounted. Fluorescent images were taken with confocal microscope Zeiss LSM510 using software LSM510 2.8. Cy3 is excited with ${ }^{2} \mathrm{He} /{ }^{10} \mathrm{Ne}$ laser (emission 543 and $633 \mathrm{~nm}$ ). FITC and Oregon Green ${ }^{\circledR} 514$ phalloidin are excited with ${ }^{18} \mathrm{Ar}$ laser (emission 458,488 or $\left.514.5 \mathrm{~nm}\right)$.

\section{MEK assay}

Phospho-MEK1/2 proteins were immunoprecipitated from total protein extracts with antiphospho-MEK1/2 antibodies and suspended in a final volumen of $20 \mu 1$ of kinase buffer ( 25 $\mathrm{mM}$ Tris- $\mathrm{HCl} \mathrm{pH} 7.5,10 \mathrm{mM} \mathrm{MgCl}_{2}, 1 \mathrm{mM}$ dithiothreitol, $2 \mu \mathrm{g} / \mathrm{ml}$ protease inhibitors [soybean trypsin inhibitor, leupeptin, aprotinin], $1 \mathrm{mM}$ phenylmethylsulfonyl fluoride, and 200

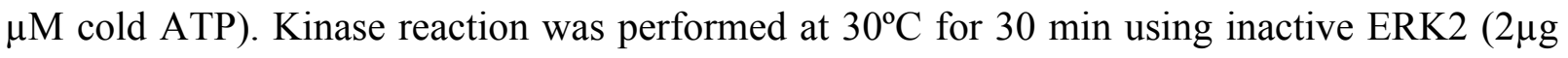

per reaction) as substrate (Cell Signalling Technology, Inc.). The reaction was stopped by adding $8 \mu 1$ of $3 x$ sample buffer and boiled for $5 \mathrm{~min}$. Samples were resolved by SDS-PAGE, transferred to a polyvinylidene difluoride membrane, and developed with antibodies antiphospho-ERK1/2.

\section{Phosphatase activity}

For the measurement of phosphatase activities associated to ERK proteins, cell lysates were immunoprecipitated for $2 \mathrm{~h}$ with anti-phospho-ERK1/2 antibodies, followed by incubation with GammaBind G Sepharose beads for further 1 hour at $4^{\circ} \mathrm{C}$. After 2 washes in RIPA buffer and 1 wash in RIPA buffer supplemented with $50 \mathrm{mM}$ imidazol $\mathrm{pH} 7.5$ and $5 \mathrm{mM}$ DTT, beads were suspended in $180 \mu$ l of RIPA-imidazol-DTT buffer and the phosphatase reaction was carried out on 96 well plates coated with fresh diluted phosphatase substrate p-NPP (para-nitrophenyl phosphate, Sigma-Aldrich, Corp.) at a concentration of $20 \mathrm{mM}$ (prepared from a $100 \mathrm{mM}$ stock 
suspended in $10 \mathrm{mM}$ glycine, $1 \mathrm{mM} \mathrm{MgCl}_{2}, 1 \mathrm{mM} \mathrm{ZnCl}_{2}$ ). Reaction was left for $15 \mathrm{~min}$ at $\mathrm{RT}$ and stopped by addition of $1 \mathrm{M} \mathrm{NaOH}$. The hydrolized p-NPP generates a yellow compound that was measured at $405 \mathrm{~nm}$ in a Microplate reader Benchmark (Bio-Rad Laboratories, Hercules, CA, USA).

To measure total phosphatase activity, total protein extracts were suspended in same RIPAimidazol-DTT buffer and added over the p-NPP-containing well.

\section{PP2A activity}

PP2A activity was determined with the "PP2A Immunoprecipitation Phosphatase Assay Kit" by Millipore (Billerica, MA), following the manufacturer's recommendations. This assay is based on the immunoprecipitation of PP2A with specific antibodies (anti-PP2A, C subunit, clone 1D6), incubation with a threonine phosphopeptide (K-R-pT-I-R-R), and assessment of the free phosphate with malachite green which generates a compound that absorbs at $655 \mathrm{~nm}$ [31].

\section{Transient transfections}

NIH3T3 cells were transiently transfected using FuGENE 6 Transfection Reagent (Roche Applied Science, Indianapolis, IN, USA) as previously described [14]. DNAs used in the transfection experiments included constructs pLTR2, pLTR2C3G, pLTR2C3G $\Delta$ Cat, pLTR2C3GSH3-b and pMEXneoHras $^{\text {Lys12 }}$ described in previous works $[13,14]$.

\section{Agonists and inhibitors}

Cells were grown in 20\% FBS or starved and then stimulated with $20 \%$ FBS for 5 min. Actin cytoskeletal polimerization inhibitor Cytochalasin D (Sigma-Aldrich, Corp.) was used at $1 \mu \mathrm{g} / \mathrm{ml}$ 
for 20 min. Okadaic acid, a specific PP2A inhibitor, was used at $2 \mathrm{nM}$ for $1 \mathrm{~h}$ and MEK inhibitor PD98059 at $50 \mu \mathrm{M}$ for $1 \mathrm{~h}$ prior FBS stimulation.

\section{Two-Hybrid}

We used MATCHMAKER Two Hybrid System 3 (Clontech Laboratories, Inc., Mountain View, CA), a two-hybrid yeast system based on the detection of transcriptional activation produced when the bait, fused to the GAL4 DNA-binding domain (DNA-BD), interacts with a library protein fused to the GAL4 activation domain (AD) [32]. When bait and library fusion proteins interact, the DNA-BD and $\mathrm{AD}$ are brought into proximity, thus activating the transcription of four reporter genes: HIS3, ADE2, MEL1 and LacZ. As bait we used a KpnI-NotI fragment, containing the SH3-b domain of C3G (aa 209-660), cloned into plasmid pGB3. The cDNA library used was from human fetal brain (Clontech, Cat. \#: HY4028AH). Following the manufacturer's specification, colonies were checked for their ability to grow in selection medium -HTLA (absence of His, Trp, Leu, Adenine) and to become blue in the presence of X$\alpha$-Gal. DNA from the selected clones was extracted and used to transform competent, ampicillin-resistant GC5 cells (Gene Choice, Frederick, MD, USA; Cat no. 62-7000-12). Plasmids were purified and sequenced using a specific oligo from the $5^{\prime}$ region of the AD protein (TACCACTACAATGGAT). Sequences were compared with NCBI (National Center for Biotechnology Information) data bases for their identification.

\section{Image processing}

Quantification of band intensity was performed by Image J version 1.24 software (developed at the National Institutes of Health). 
Statistical analysis.

Data are represented as mean \pm s.d. As comparisons were made between two experimental groups, an unpaired Student's t-test was used. Results were considered significant when $\mathrm{p}<0.05$. 


\section{Results}

Overexpression of $C 3 G$ and C3GACat inhibits in vitro ERK phosphorylation without affecting MEK1 activation

We have demonstrated previously that $\mathrm{C} 3 \mathrm{G}$ overexpression does not affect Ras, Raf1 and MEK1 activation (estimated by the level of phospho-MEK proteins), while it decreases the level of ERK1/2 phosphorylation [14]. To further characterize whether C3G is affecting MEK1 activity on ERK1/2 proteins, we performed in vitro kinase assays on phospho-MEK1 immunoprecipitates of total cell lysates of $\mathrm{pLTR}_{2}+\mathrm{Hras}^{\mathrm{Lys} 12}-, \mathrm{C} 3 \mathrm{G}+\mathrm{Hras}{ }^{\text {Lys12 }}$ - and $\mathrm{C} 3 \mathrm{G} \Delta \mathrm{Cat}+\mathrm{Hras}^{\mathrm{Lys} 12}-\mathrm{NIH} 3 \mathrm{~T} 3$ stable transfectants, using inactive ERK2 as substrate. PD98059 was used as negative control of MEK activity. Fig. 1 (panel a) shows that the level of phosphorylated ERK2 substrate is lower in FBS-stimulated cells overexpressing C3G and C3G $\Delta$ Cat in comparison with cells carrying empty pLTR2 vector, whereas the level of immunoprecipitated phospho-MEK remains unaffected (panel b). In agreement with previous results, total cell lysates showed the same reduction in phospho-ERK1/2 in both C3G clones (panel c) [14]. Control expression of MEK1, ERK1/2 and exogenous DNAs are shown in panels d-g. It is known that the level of phosphorylated MEK is positively correlated with the ability to phosphorylate and activate ERK proteins [33]. Based on that, our data showing that C3G does not affect MEK1 phosphorylation (and consequent activity) while affecting ERK phosphorylation, suggest that cellular phosphatases present in the MEK1 immunoprecipitates are dephosphorylating ERK proteins without affecting phospho-MEK1. This implies that C3G might be regulating cellular phosphatases acting specifically on phospho-ERK. 
Ectopic expression of C3G and C3GACat mutant activates ERK-associated cellular phosphatases

To probe whether this is the case, we first measured total phosphatase activity in cell lysates of NIH3T3 clones overexpressing $\mathrm{C} 3 \mathrm{G}$ or $\mathrm{C} 3 \mathrm{G} \Delta \mathrm{Cat}$ together with $\mathrm{Hras}^{\mathrm{Lys} 12}$ by the p-NPP method. Fig. 2A shows that the overexpression of both $\mathrm{C} 3 \mathrm{G}$ and $\mathrm{C} 3 \mathrm{G} \Delta \mathrm{Cat}$ in $\mathrm{Hras}^{\mathrm{Lys} 12}$ expressing cells systematically increased cellular phosphatase activity, as compared to clones carrying control vector pLTR2, both in serum-starved and in FBS stimulation conditions. These results indicate that $\mathrm{C} 3 \mathrm{G}$ upregulates phosphatase activities by a mechanism that is independent of its GEF domain, which suggests this effect could be related to its transformation suppressor activity.

To further understand the mechanisms involved in this novel, undescribed, function of C3G, and considering its inhibitory effect on Hras ${ }^{\text {Lys12 }}$-induced ERK1/2 phosphorylation, we investigated whether $\mathrm{C} 3 \mathrm{G}$ affects phosphatases that regulate ERK activity. It is known that proteins implicated in ERK regulation (MEK, phosphatases), and also substrates like transcription factors, form a stable complex with ERK proteins [15, 34, 35]. Therefore, to study the effect of $\mathrm{C} 3 \mathrm{G}$ on ERK1/2/MAPK phosphatases, lysates of pLTR2+Hras ${ }^{\text {Lys12 }}$, $\mathrm{C} 3 \mathrm{G}+\mathrm{Hras}^{\mathrm{Lys} 12}$ - or $\mathrm{C} 3 \mathrm{G} \Delta \mathrm{Cat}+\mathrm{Hras}^{\mathrm{Lys} 12}$-expressing clones were immunoprecipitated with antip-MAPK p44-p42 (T202/Y204) antibodies and the associated phosphatase activity measured by the p-NPP method. As illustrated in Fig. 2B, ERK-associated phosphatase activity was significantly higher in $\mathrm{C} 3 \mathrm{G}$ and $\mathrm{C} 3 \mathrm{G} \Delta \mathrm{Cat}$ expressing clones, as compared with pLTR2transfected controls. This effect was more pronounced under starvation conditions and with the C3G $\Delta$ Cat mutant. These results suggest that ERK1/2 specific phosphatases are likely mediators of C3G inhibitory effect on ERK phosphorylation. Notice that the fold increase in total phosphatases due to $\mathrm{C} 3 \mathrm{G} / \mathrm{C} 3 \mathrm{G} \Delta \mathrm{Cat}$ overexpression is similar to the fold increase 
observed in ERK immunoprecipitates, suggesting that C3G is probably acting exclusively on ERK-associated phosphatases.

\section{C3G upregulates PP2A activity}

It is well known that PP2A family are the most abundant cellular phosphatases acting on most components of growth factor signaling cascades [36]. Indeed, PP2A associates with all members of the Raf1-ERK1/2 pathway, including the scaffold protein Ksr-1 [20-22]. To investigate whether C3G specifically regulates phosphatases of the PP2A family, we measured PP2A activity in our $\mathrm{C} 3 \mathrm{G}$ and Hras ${ }^{\mathrm{Lys} 12}$ overexpressing clones incubated in the presence or absence of $2 \mathrm{nM}$ okadaic acid (OA), a concentration that specifically inhibits PP2A but not PP1 phosphatases [37], Fig. 3A shows that, indeed, both $\mathrm{C} 3 \mathrm{G}$ and $\mathrm{C} 3 \mathrm{G} \Delta \mathrm{Cat}$ upregulate PP2A activity and, as expected, treatment with OA inhibits C3G-mediated PP2A activation. In agreement with this result, $\mathrm{C} 3 \mathrm{G}$ and $\mathrm{C} 3 \mathrm{G} \Delta \mathrm{Cat}$ significantly reduced the levels of phosphorylated (inactive) PP2A (Fig. 3B), further indicating that both $\mathrm{C} 3 \mathrm{G}$ and $\mathrm{C} 3 \mathrm{G} \Delta \mathrm{Cat}$ stimulate PP2A activity. Furthermore, C3G and C3G $\Delta$ Cat inhibition of PP2A phosphorylation was reverted by OA treatment (Fig. 3C), which is in agreement with previous findings [38, 39].

\section{$P P 2 A$ and C3G form a complex at the subcortical actin cytoskeleton}

To gain an insight into the possible functional relationship between $\mathrm{C} 3 \mathrm{G}$ and PP2A, we studied whether these two proteins interact. Thus, we performed immunoprecipitation studies with anti-C3G or anti-PP2A antibodies and detected the presence of C3G and PP2A by immunoblotting. As shown in Fig. 4A-B, C3G and PP2A were present in both immunoprecipitates, indicating that these two proteins form a complex. The amount of PP2A that interacts with $\mathrm{C} 3 \mathrm{G}$ is correlated with the level of expression of the $\mathrm{C} 3 \mathrm{G}$ form. Thus, Fig. 4B shows correlation between the amount of the $\mathrm{C} 3 \mathrm{G}$ mutant expressed and the amount of 
PP2A detected in the corresponding C3G immunoprecipitate. Consistently, mutant $\mathrm{C} 3 \mathrm{G} \Delta \mathrm{Cat}$, whose detection level with available antibodies is rather poor (Fig. 4B and 1f) displays very low coprecipitation with PP2A. On the contrary, mutant C3G-SH3b, containing just the SH3binding (SH3-b) domain (aa 209-660) of C3G interacts with the larger amount of PP2A, in agreement with its higher expression. This interaction between $\mathrm{C} 3 \mathrm{G}$ and PP2A is not an artefact due to $\mathrm{C} 3 \mathrm{G}$ overexpression, as it was also observed with endogenous proteins (pLTR2+HrasT cells), neither oncogenic Ras-dependent, as it is also clearly detectable in cells just carrying vector pLTR2, although, in agreement with results in Figure 4B, the interaction increases in cells transfected with pLTR2C3G construct (data not shown). Additionally, these results demonstrate that the $\mathrm{SH} 3-\mathrm{b}$ domain of $\mathrm{C} 3 \mathrm{G}$ is sufficient for the association with PP2A.

To further corroborate these interactions we studied whether these two proteins exhibit a similar cellular distribution. Indeed, immunofluorescence experiments showed a colocalization between $\mathrm{C} 3 \mathrm{G}$ or $\mathrm{C} 3 \mathrm{G} \triangle \mathrm{Cat}$ and PP2A (Fig. 4C, CytD - panels), in agreement with the immunoprecipitation/immunoblotting experiments. Importantly, immunofluorescence images show similar signal intensity and distribution patterns of $\mathrm{C} 3 \mathrm{G}$ and $\mathrm{C} 3 \mathrm{G} \Delta \mathrm{Cat}$. The variations in $\mathrm{C} 3 \mathrm{G}$ and $\mathrm{C} 3 \mathrm{G} \Delta \mathrm{Cat}$ expression observed in the immunoblots are probably due to differences in the recognition of both protein species by the $\mathrm{C} 3 \mathrm{G}$ antibody used in Western blot, rather than to real differences in expression. This is further supported by the fact that both clones also show similar RNA expression levels (data not shown).

\section{PP2A mediates C3G inhibition of ERK phosphorylation}

The above results demonstrated a functional relationship between C3G and PP2A. On the other hand $\mathrm{C} 3 \mathrm{G}$ upregulates ERK-associated phosphatase activities (Fig. 2B). Moreover, the association between PP2A and phospho-MEK or phospho-ERK was augmented in C3G- and C3G $\triangle$ Cat-overexpressing cells (Fig. 5A). All these results suggest that PP2A could be 
involved, at least in part, in the inhibitory effect of $\mathrm{C} 3 \mathrm{G}$ on ERK phosphorylation. To prove this hypothesis we determined the levels of phospho-ERK in C3G overexpressing cells in the presence of $2 \mathrm{nM}$ okadaic acid (OA). Fig. 5B shows that, indeed, the inhibitory effect of $\mathrm{C} 3 \mathrm{G}$ on ERK phosphorylation was reverted by treatment with OA, which definitively establishes a link between PP2A and the C3G-mediated inhibition on ERK phosphorylation. Besides, there is a correlation between the decrease in phospho-ERK and the decrease of phospho (inactive)PP2A levels in the C3G-overexpressing cells.

All these result suggest that C3G may be forming a complex with PP2A, ERK and MEK. It is known that Ksr-1 acts as a scaffold for the Ras-ERK signaling pathway interacting with the kinase components of this pathway like MEK and ERK [40]. PP2A is also a component of the Ksr-1 scaffolding complex; in fact, PP2A dephosphorylate Ksr-1 in S392, a requirement for Ksr-1-mediated ERK activation [21]. To investigate whether C3G is also a member of the Ksr1 complex, we performed immunoblotting analysis on $\mathrm{C} 3 \mathrm{G}$ immunoprecipitates with anti-Ksr1 antibodies. Fig. 5C shows that, indeed, $\mathrm{Ksr}-1$ interacts with $\mathrm{C} 3 \mathrm{G}$ and $\mathrm{C} 3 \mathrm{G} \Delta \mathrm{Cat}$. The amount of Ksr-1 that coprecipitates correlates with the amount of PP2A found in the same immunoprecipitates.

\section{C3G suppressor activity maps to the subcortical actin cytoskeleton}

Recently, it has been shown that endogenous Tyr 504 phosphorylated C3G localizes to the subcortical actin cytoskeleton and the Golgi complex [28]. To determine whether C3G suppressor activity correlates with any particular subcellular location, we studied the distribution of $\mathrm{C} 3 \mathrm{G}$ and $\mathrm{C} 3 \mathrm{G} \Delta \mathrm{Cat}$ mutant in these organelles in cells overexpressing $\mathrm{C} 3 \mathrm{G}$ or $\mathrm{C} 3 \mathrm{G} \Delta \mathrm{Cat}$ in combination with $\mathrm{Hras}^{\mathrm{Lys} 12}$. As shown in Fig. 6A (CytD - panels), both $\mathrm{C} 3 \mathrm{G}$ and $\mathrm{C} 3 \mathrm{G} \Delta \mathrm{Cat}$ colocalize with actin at the subcortical cytoskeleton. These results were further confirmed by treatment with the actin polymerization inhibitor cytochalasin $\mathrm{D}$. Thus, in the presence of cytochalasin $\mathrm{D}$ the fraction 
of $\mathrm{C} 3 \mathrm{G}$ and $\mathrm{C} 3 \mathrm{G} \Delta \mathrm{Cat}$ that interacts with actin looses their cortical distribution and accumulates in the same positions as depolymerised actin, further confirming the authenticity of this interaction (Fig. 6A, CytD + panels). Subcellular fractioning using Subcellular proteome extraction kit by Calbiochem showed similar cytoplasmic, membrane and cytoskeletal C3G location both in wild type and C3G-overexpressing cells (data not shown). Thus, the apparent staining of C3G in the nucleus of control pLTR2 cells is an occasional artefact of the technique probably due to the low level of expression of endogenous $\mathrm{C} 3 \mathrm{G}$ in these cells.

In contrast, $\mathrm{C} 3 \mathrm{G}$, but not $\mathrm{C} 3 \mathrm{G} \Delta \mathrm{Cat}$, colocalized with the Golgi complex (Fig. 6B), suggesting that the exchange activity is the only known $\mathrm{C} 3 \mathrm{G}$ function associated to this organelle. This is in agreement with previously described Rap1 distribution in Golgi [41-43].

To further demonstrate the C3G-actin interplay, we immunoprecipitated total cell lysates from permanently transfected pLTR $2+\mathrm{Hras}^{\mathrm{Lys} 12}, \mathrm{C} 3 \mathrm{G}+\mathrm{Hras}^{\mathrm{Lys} 12}$ or $\mathrm{C} 3 \mathrm{G} \Delta \mathrm{Cat}+\mathrm{Hras}^{\mathrm{Lys} 12}$ clones with anti-C3G (H-300) antibodies and analyzed the interaction by immunoblotting with anti-actin (c11) antibodies. Fig. $6 \mathrm{C}$ clearly shows an increase in the amount of actin that precipitates in the $\mathrm{C} 3 \mathrm{G}$ and $\mathrm{C} 3 \mathrm{G} \Delta$ Cat-overexpressing clones, as compared with the clone carrying pLTR2 vector alone. The interaction between C3G and actin is direct, as demonstrated by two-hybrid analysis, and is mediated by the SH3-b domain (data not shown).

\section{C3G suppressor activity requires an integral subcortical actin cytoskeleton}

To better ascertain the correlation between $\mathrm{C} 3 \mathrm{G}$ location at the subcortical actin cytoskeleton and its suppressor activity on $\mathrm{Hras}^{\mathrm{Lys12}}$ transformation, we studied the effect of cytochalasin D on C3G and $\mathrm{C} 3 \mathrm{G} \Delta$ Cat-mediated inhibition of ERK phosphorylation. Fig. 7 shows that the inhibitory effect of $\mathrm{C} 3 \mathrm{G}$ and $\mathrm{C} 3 \mathrm{G} \Delta \mathrm{Cat}$ on Ras-mediated ERK phosphorylation was reverted in the presence of cytochalasin D, suggesting that the inhibitory effect of $\mathrm{C} 3 \mathrm{G}$ on ERK activation requires an intact subcortical actin cytoskeleton. Furthermore, cytochalasin D treatment did not disrupt the 
association between C3G and PP2A (Fig. 4, CytD + panels) indicating that both proteins interact with actin and form a complex at the subcortical cytoskeleton.

In summary, all these results suggest that the $\mathrm{C} 3 \mathrm{G}$ fraction bound to actin at the subcortical cytoskeleton interacts with, and activates phosphatases of the PP2A family that, in turn, dephosphorylate ERK proteins, probably contributing to the observed inhibition of Ras-mediated transformation. 


\section{Discussion}

In previous work, our group has demonstrated that $\mathrm{C} 3 \mathrm{G}$ exerts a role as transformation suppressor over several oncogenes. Also, we described the suppression mechanism as a result of the inhibition of ERK phosphorylation and, consequently, reduction in cyclin A expression, whose final effect is the loss of the anchorage-independent growth ability of the oncogenic cells $[13,14]$. Even though C3G reduces the number of sis (PDGF), ras $^{\text {Lys12 }}$ and v-raf-induced foci, $\mathrm{C} 3 \mathrm{G}$ overexpression appears to affect exclusively a specific downstream step in the cascade, the ERK phosphorylation. Therefore, the fact that $\mathrm{C} 3 \mathrm{G}$ has no effect on MEK1 activity suggests that $\mathrm{C} 3 \mathrm{G}$ could be acting through the activation of cellular phosphatases. The present work demonstrates that this is, indeed, the case; both $\mathrm{C} 3 \mathrm{G}$ and $\mathrm{C} 3 \mathrm{G} \Delta \mathrm{Cat}$ overexpression increased total cellular phosphatase activities, and more specifically ERKassociated phosphatases, which is in agreement with the proposed hypothesis. It is worth mentioning that, although the quantitative increases in phosphatase activities are not very high, results are statistically significant under different experimental conditions: FBS-stimulated cells in total phosphatase activity (Fig. 2A) and serum-starved cells in ERK-associated phosphatase activity (Fig. 2B). Besides, the standard deviations are low in all experimental situations supporting the significance of the results.

Among the various phosphatases regulating ERK phosphorylation, numerous evidences point at members of the PP2A family as mediators of the $\mathrm{C} 3 \mathrm{G}$ suppression function: (i) PP2A is activated by $\mathrm{C} 3 \mathrm{G}$, as visualized by malachite green assay and a reduction in the levels of phospho-(inactive)-PP2A; (ii) interactions PP2A-MEK1 and PP2A-ERK are augmented in C3G-expressing clones; (iii) PP2A coprecipitates and colocalizes with C3G; (iv) and the most important fact that definitively establishes a link between PP2A and the suppressor function of C3G: okadaic acid (at a dose that specifically inhibits PP2A) reverts the inhibitory effect of 
$\mathrm{C} 3 \mathrm{G}$ on ERK phosphorylation. It is important to point out that PP2A is found in $\mathrm{C} 3 \mathrm{G}$ immunoprecipitates in control, pLTR2-transfected cells, indicating that the C3G-PP2A interaction is physiological, and not an artefact related to $\mathrm{C} 3 \mathrm{G}$ or Hras ${ }^{\text {Lys12 }}$ overexpression (Fig. 4B and 5C and data not shown).

It is known that, depending on the holoenzyme composition, PP2A can act on MEK, ERK or both $[18,27,44,45]$. In our case, it seems clear that the C3G-regulated PP2A holoenzyme acts exclusively on phospho-ERK without affecting MEK or other steps in the cascade. This behaviour has recently been identified in holoenzymes containing a $\mathrm{B}^{\prime}$ family member as regulatory subunit [45].

Our results clearly demonstrated an association between $\mathrm{C} 3 \mathrm{G}$ and PP2A. Moreover, a C3G fragment just containing the SH3-binding domain (aa 209-660) is sufficient for the association with PP2A, in concordance with the previously described role of this domain in the transformation suppression effect of $\mathrm{C} 3 \mathrm{G}$.

Two-hybrid experiments demonstrated that the SH3-b domain of $\mathrm{C} 3 \mathrm{G}$ interacts with two member of the actin family: $\beta$-actin and $\gamma$-actin (data not shown). These results are in concordance with those published by Radha and coworkers showing that the subcortical actin cytoskeleton is one of the subcellular compartments, together with the Golgi apparatus, where activated C3G is located [28]. Accordingly, actin was detected in C3G-immunoprecipitates of both $\mathrm{C} 3 \mathrm{G}$ and $\mathrm{C} 3 \mathrm{G} \Delta$ Cat-expressing clones and these interactions were also confirmed by immunofluorescence. The apparent lack of colocalization between $\mathrm{C} 3 \mathrm{G}$ and actin in the pLTR2+Hras ${ }^{\text {Lys12 }}$-transfected clone is probably due to the low expression level of endogenous $\mathrm{C} 3 \mathrm{G}$ in these cells, as subcellular fractioning showed equal distribution of endogenous and ectopic $\mathrm{C} 3 \mathrm{G}$ in the cytoskeletal fraction (data not shown). In addition, the fact that the colocalization between the $\mathrm{C} 3 \mathrm{G}$ clones and actin remains stable in cells treated with the actin polymerization inhibitor cytochalasin D further confirms the authenticity of these interactions 
and suggests a functional relationship between these two proteins at this subcellular compartment.

Nevertheless, only full-length $\mathrm{C} 3 \mathrm{G}$, but not $\mathrm{C} 3 \mathrm{G} \Delta$ Cat, colocalizes with Golgi. As $\mathrm{C} 3 \mathrm{G} \Delta \mathrm{Cat}$ conserves all the potential for suppressing oncogenic transformation [13], these results indicate that the transformation suppression function of $\mathrm{C} 3 \mathrm{G}$ is associated to the subcortical actin cytoskeleton. Indeed, treatment with cytochalasine D prevents C3G-mediated ERK inhibition, which suggests $\mathrm{C} 3 \mathrm{G}$ requires an intact subcortical cytoskeleton structure to exert its suppression function.

Based on these results, a very attractive theory is that $\mathrm{C} 3 \mathrm{G}$ could perform differential, specific functions in these two compartments. Thus, the fraction of $\mathrm{C} 3 \mathrm{G}$ located at the Golgi apparatus, where Rap1 proteins are predominantly located [41-43], would function as exchange factor for these GTPases, while the fraction of $\mathrm{C} 3 \mathrm{G}$ sited at the subcortical actin cytoskeleton would be responsible for events related with the transformation suppression.

Both PP2A and MEK are constitutively associated to the protein scaffold of the Ras-ERK pathway, Ksr-1 [46]. However, less than 5\% of the Ras pathway kinases, including Raf1, MEK and ERK are associated with Ksr-1 even under maximal stimulation conditions [46, 47]. Also, in the absence of mitogenic signals, the Ksr-1 complex is inactive and sequestered in Tritoninsoluble compartments [46]. The fact that $\mathrm{C} 3 \mathrm{G}$ increases the association between PP2A and MEK or ERK, together with the fact that C3G itself interacts with Ksr-1, suggest that the C3G fraction associated to the subcortical actin cytoskeleton might contribute to the stabilization of the complex and/or its recruitment to this submembranal location, which result in an increase in the PP2A-mediated ERK dephosphorylation.

We propose a model where the fraction of $\mathrm{C} 3 \mathrm{G}$ localized at the subcortical actin cytoskeleton interacts and activates PP2A which in turns, dephosphorylates and inactivates ERK. In the context of Ras-transformed cells, this results in the inhibition of cyclin A 
expression and, consequently, loss of the transformed cells ability to survive under nonadherent conditions $[13,14]$. Possibly all these molecules are part of a complex where a scaffold protein, like Ksr-1, integrates all the components. Additional studies are needed to identify the specific PP2A holoenzyme regulated by $\mathrm{C} 3 \mathrm{G}$ that mediates its transformation suppression effects, as well as, to determine the mechanism by which C3G activates PP2A. 


\section{Acknowledgments}

This work was supported by grants SAF2003-04177 and GEN2003-20239-C06-02 from MEC, Spain, FIS-FEDER PI030651, PI041324 and PI061274 from ISCIII, MSC, Spain, as well as institutional support from Redes Temáticas (C03/10 and RD06/0020/0000) de investigación en cáncer from ISCIII, MSC, Spain. S. M-E is a postodoctoral fellow supported by grant GEN2003-20239-C06-02. C.G. was supported by the Ramón y Cajal Program from the Spanish Ministry of Education. 


\section{References}

[1] T. Gotoh, S. Hattori, S. Nakamura, H. Kitayama, M. Noda, Y. Takai, K. Kaibuchi, H. Matsui, O. Hatase, H. Takahashi, T. Kurata, M. Matsuda, Identification of Rap1 as a target for the Crk SH3 domain-binding guanine nucleotide-releasing factor $\mathrm{C} 3 \mathrm{G}$, Mol. Cell. Biol. 15 (1995) 6746-6753.

[2] T. Gotoh, Y. Niino, M. Tokuda, O. Hatase, S. Nakamura, M. Matsuda, S. Hattori, Activation of R-Ras by Ras-guanine nucleotide-releasing factor, J. Biol. Chem. 272 (1997) 18602-18607.

[3] R. de Jong, A. van Wijk, N. Heisterkamp, J. Groffen, C3G is tyrosine-phosphorylated after integrin-mediated cell adhesion in normal but not in Bcr/Abl expressing cells, Oncogene 17 (1998) 2805-2810.

[4] A. Arai, Y. Nosaka, H. Kohsaka, N. Miyasaka, O. Miura, CrkL activates integrinmediated hematopoietic cell adhesion through the guanine nucleotide exchange factor C3G, Blood 93 (1999) 3713-3722.

[5] A. Arai, Y. Nosaka, E. Kanda, K. Yamamoto, N. Miyasaka, O. Miura, Rap1 is activated by erythropoietin or interleukin-3 and is involved in regulation of betal integrinmediated hematopoietic cell adhesion, J. Biol. Chem. 276 (2001) 10453-10462.

[6] N. Uemura, J.D. Griffin, The adapter protein Crkl links Cbl to C3G after integrin ligation and enhances cell migration, J. Biol. Chem. 274 (1999) 37525-37532.

[7] Y. Ohba, K. Ikuta, A. Ogura, J. Matsuda, N. Mochizuki, K. Nagashima, K. Kurokawa, B.J. Mayer, K. Maki, J. Miyazaki, M. Matsuda, Requirement for C3G-dependent Rap1 activation for cell adhesion and embryogenesis, EMBO J. 20 (2001) 3333-3341.

[8] Y. Nosaka, A. Arai, N. Miyasaka, O. Miura, CrkL mediates Ras-dependent activation of the Raf/ERK pathway through the guanine nucleotide exchange factor $\mathrm{C} 3 \mathrm{G}$ in 
hematopoietic cells stimulated with erythropoietin or interleukin-3, J. Biol. Chem. 274 (1999) 30154-30162.

[9] S. Ishimaru, R. Williams, E. Clark, H. Hanafusa, U. Gaul, Activation of the Drosophila C3G leads to cell fate changes and overproliferation during development, mediated by the RAS-MAPK pathway and RAP1, EMBO J. 18 (1999) 145-155.

[10] S. Kao, R.K. Jaiswal, W. Kolch, G.E. Landreth, Identification of the mechanisms regulating the differential activation of the mapk cascade by epidermal growth factor and nerve growth factor in PC12 cells, J. Biol. Chem. 276 (2001) 18169-18177.

[11] A. Arai, E. Kanda, O. Miura, Rac is activated by erythropoietin or interleukin-3 and is involved in activation of the Erk signaling pathway, Oncogene 21 (2002) 2641-2651.

[12] C.S. Buensuceso, T.E. O'Toole, The association of CRKII with C3G can be regulated by integrins and defines a novel means to regulate the mitogen-activated protein kinases, J. Biol. Chem. 275 (2000) 13118-13125.

[13] C. Guerrero, A. Fernandez-Medarde, J.M. Rojas, J. Font de Mora, L.M. Esteban, E. Santos, Transformation suppressor activity of C3G is independent of its CDC25homology domain, Oncogene 16 (1998) 613-624.

[14] C. Guerrero, S. Martin-Encabo, A. Fernandez-Medarde, E. Santos, C3G-mediated suppression of oncogene-induced focus formation in fibroblasts involves inhibition of ERK activation, cyclin A expression and alterations of anchorage-independent growth, Oncogene 23 (2004) 4885-4893.

[15] S.M. Keyse, Protein phosphatases and the regulation of mitogen-activated protein kinase signalling, Curr. Opin. Cell Biol. 12 (2000) 186-192.

[16] B. Zhou, Z.X. Wang, Y. Zhao, D.L. Brautigan, Z.Y. Zhang, The specificity of extracellular signal-regulated kinase 2 dephosphorylation by protein phosphatases, J. Biol. Chem. 277 (2002) 31818-31825. 
[17] S. Wera, B.A. Hemmings, Serine/threonine protein phosphatases, Biochem J. 311 (Pt 1) (1995) 17-29.

[18] V. Janssens, J. Goris, Protein phosphatase 2A: a highly regulated family of serine/threonine phosphatases implicated in cell growth and signalling, Biochem J. 353 (2001) 417-439.

[19] V. Janssens, J. Goris, C. Van Hoof, PP2A: the expected tumor suppressor, Curr. Opin. Genet. Dev. 15 (2005) 34-41.

[20] Q. Liu, P.A. Hofmann, Protein phosphatase 2A-mediated cross-talk between p38 MAPK and ERK in apoptosis of cardiac myocytes, Am. J. Physiol. Heart Circ. Physiol. 286 (2004) H2204-H2212.

[21] S. Ory, M. Zhou, T.P. Conrads, T.D. Veenstra, D.K. Morrison, Protein phosphatase 2A positively regulates Ras signaling by dephosphorylating KSR1 and Raf-1 on critical 143-3 binding sites, Curr. Biol. 13 (2003) 1356-1364.

[22] D. Abraham, K. Podar, M. Pacher, M. Kubicek, N. Welzel, B.A. Hemmings, S.M. Dilworth, H. Mischak, W. Kolch, M. Baccarini, Raf-1-associated protein phosphatase 2A as a positive regulator of kinase activation, J. Biol. Chem. 275 (2000) 22300-22304.

[23] D.A. Wassarman, N.M. Solomon, H.C. Chang, F.D. Karim, M. Therrien, G.M. Rubin, Protein phosphatase 2A positively and negatively regulates Ras1-mediated photoreceptor development in Drosophila, Genes Dev. 10 (1996) 272-278.

[24] A.M. Silverstein, C.A. Barrow, A.J. Davis, M.C. Mumby, Actions of PP2A on the MAP kinase pathway and apoptosis are mediated by distinct regulatory subunits, Proc. Natl. Acad. Sci. U S A 99 (2002) 4221-4226.

[25] S. Strack, Overexpression of the protein phosphatase 2A regulatory subunit Bgamma promotes neuronal differentiation by activating the MAP kinase (MAPK) cascade, J. Biol. Chem. 277 (2002) 41525-41532. 
[26] M.J. Van Kanegan, D.G. Adams, B.E. Wadzinski, S. Strack, Distinct protein phosphatase $2 \mathrm{~A}$ heterotrimers modulate growth factor signaling to extracellular signalregulated kinases and Akt, J. Biol. Chem. 280 (2005) 36029-36036.

[27] D.G. Adams, R.L. Coffee, Jr., H. Zhang, S. Pelech, S. Strack, B.E. Wadzinski, Positive Regulation of Raf1-MEK1/2-ERK1/2 Signaling by Protein Serine/Threonine Phosphatase 2A Holoenzymes, J. Biol. Chem. 280 (2005) 42644-42654.

[28] V. Radha, A. Rajanna, G. Swarup, Phosphorylated guanine nucleotide exchange factor $\mathrm{C} 3 \mathrm{G}$, induced by pervanadate and Src family kinases localizes to the Golgi and subcortical actin cytoskeleton, BMC Cell Biol. 5 (2004) 31.

[29] F.J. Zwartkruis, J.L. Bos, Ras and Rap1: two highly related small GTPases with distinct function, Exp. Cell Res. 253 (1999) 157-165.

[30] R. Shivakrupa, V. Radha, C. Sudhakar, G. Swarup, Physical and functional interaction between Hck tyrosine kinase and guanine nucleotide exchange factor $\mathrm{C} 3 \mathrm{G}$ results in apoptosis, which is independent of C3G catalytic domain, J. Biol. Chem. 278 (2003) $52188-52194$.

[31] L.A. Pinna, A. Donella-Deana, Phosphorylated synthetic peptides as tools for studying protein phosphatases, Biochim. Biophys. Acta 1222 (1994) 415-431.

[32] S. Fields, O. Song, A novel genetic system to detect protein-protein interactions, Nature 340 (1989) 245-246.

[33] C.F. Zheng, K.L. Guan, Properties of MEKs, the kinases that phosphorylate and activate the extracellular signal-regulated kinases, J. Biol. Chem. 268 (1993) 2393323939.

[34] T. Tanoue, E. Nishida, Docking interactions in the mitogen-activated protein kinase cascades, Pharmacol. Ther. 93 (2002) 193-202. 
[35] T. Tanoue, T. Yamamoto, E. Nishida, Modular structure of a docking surface on MAPK phosphatases, J. Biol. Chem. 277 (2002) 22942-22949.

[36] T.A. Millward, S. Zolnierowicz, B.A. Hemmings, Regulation of protein kinase cascades by protein phosphatase 2A, Trends Biochem. Sci. 24 (1999) 186-191.

[37] M.M. Gehringer, Microcystin-LR and okadaic acid-induced cellular effects: a dualistic response, FEBS Lett. 557 (2004) 1-8.

[38] J. Chen, B.L. Martin, D.L. Brautigan, Regulation of protein serine-threonine phosphatase type-2A by tyrosine phosphorylation, Science 257 (1992) 1261-1264.

[39] J. Chen, S. Parsons, D.L. Brautigan, Tyrosine phosphorylation of protein phosphatase 2A in response to growth stimulation and v-src transformation of fibroblasts, J. Biol. Chem. 269 (1994) 7957-7962.

[40] D.K. Morrison, KSR: a MAPK scaffold of the Ras pathway?, J. Cell Sci. 114 (2001) $1609-1612$.

[41] Y. Liao, T. Satoh, X. Gao, T.G. Jin, C.D. Hu, T. Kataoka, RA-GEF-1, a guanine nucleotide exchange factor for Rap1, is activated by translocation induced by association with Rap1*GTP and enhances Rap1-dependent B-Raf activation, J. Biol. Chem. 276 (2001) 28478-28483.

[42] C. Wu, C.F. Lai, W.C. Mobley, Nerve growth factor activates persistent Rap1 signaling in endosomes, J. Neurosci. 21 (2001) 5406-5416.

[43] J.L. Bos, J. de Rooij, K.A. Reedquist, Rap1 signalling: adhering to new models, Nat. Rev. Mol. Cell. Biol. 2 (2001) 369-377.

[44] J. Westermarck, S.P. Li, T. Kallunki, J. Han, V.M. Kahari, p38 mitogen-activated protein kinase-dependent activation of protein phosphatases 1 and 2A inhibits MEK1 and MEK2 activity and collagenase 1 (MMP-1) gene expression, Mol. Cell. Biol. 21 (2001) 2373-2383. 
[45] C. Letourneux, G. Rocher, F. Porteu, B56-containing PP2A dephosphorylate ERK and their activity is controlled by the early gene IEX-1 and ERK, EMBO J. 25 (2006) 727738.

[46] W. Kolch, Coordinating ERK/MAPK signalling through scaffolds and inhibitors, Nat. Rev. Mol. Cell Biol. 6 (2005) 827-837.

[47] R.L. Kortum, R.E. Lewis, The molecular scaffold KSR1 regulates the proliferative and oncogenic potential of cells, Mol. Cell. Biol. 24 (2004) 4407-4416. 


\section{Figure legends}

Fig. 1. C3G affects ERK phosphorylation but not MEK1 activity. NIH3T3 clones overexpressing HrasT alone or in combination with $\mathrm{C} 3 \mathrm{G}$ or $\mathrm{C} 3 \mathrm{G} \Delta \mathrm{Cat}$ were starved for $24 \mathrm{~h}$, pretreated, when indicated, with $50 \mu \mathrm{M}$ PD98059 for $1 \mathrm{~h}$ and then stimulated with $20 \%$ FBS for 5 min. Lysates were immunoprecipitated with anti-phospho-MEK1/2 antibodies and then subjected to in vitro kinase reactions using inactive ERK2 protein as substrate. Phosphorylated ERK proteins were detected with anti-phospho-ERK antibodies (panel a), then the blot was stripped and incubated with anti-phospho-MEK1/2 antibodies (panel b). Phospho-ERK1/2 (panel c), total MEK1 (panel d), total ERK1/2 (panel e), C3G/C3G $\Delta$ Cat (panel f) and Hras ${ }^{\text {Lys12 }}$ (panel g) expressions were detected in total cell lysates with corresponding antibodies. The panels are representative of three independent experiments. HrasT (transforming Hras): Hras $^{\text {Lys12 }}$; PD: PD98059; FBS: fetal bovine serum; b: beads incubated with total cell lysate.

Fig. 2. C3G upregulates phosphatase activities (A) Graphic representing relative total phosphatase activity in clones overexpressing HrasT alone or in combination with $\mathrm{C} 3 \mathrm{G}$ or C3G $\Delta$ Cat, measured as absorbance at $405 \mathrm{~nm}$. Cells were serum starved for 20-22 h or starved and then stimulated with $20 \%$ FBS for 5 min. ${ }^{*}$ p $<0.05$ versus pLTR2 + HrasT in $20 \%$ FBS stimulation condition. The histogram represents the media and s.d. of three independent experiments. (B) Upper: Graphic representing relative phosphatase activity associated to Thr 202 and Tyr 204 phosphorylated ERK1/2 proteins in clones overexpressing HrasT alone or in combination with $\mathrm{C} 3 \mathrm{G}$ or $\mathrm{C} 3 \mathrm{G} \Delta \mathrm{Cat}$, measured as absorbance at $405 \mathrm{~nm}$. Cells were serum starved for 20-22 $\mathrm{h}$ or starved and then stimulated with $20 \%$ FBS for 5 min. ${ }^{*} \mathrm{p}<0.05$ versus pLTR2 + HrasT in starved condition. The graphic corresponds to three different experiments.

HrasT: Hras ${ }^{\text {Lys12 }}$. Lower: Representative Western blot of the same lysates $(20 \mu \mathrm{g})$ used for the 
phosphatase assays showing similar amounts of total ERK1/2 in all samples. Numbers indicate the samples order.

Fig. 3. C3G upregulates PP2A activity. (A) Upper: Graphic representing relative PP2A activity in clones overexpressing $\mathrm{Hras}^{\mathrm{Lys} 12}$ alone or in combination with $\mathrm{C} 3 \mathrm{G}$ or $\mathrm{C} 3 \mathrm{G} \Delta \mathrm{Cat}$, measured as absorbance at $655 \mathrm{~nm}$. Subconfluent cell cultures were serum starved for $20-22 \mathrm{~h}$ and then treated with $2 \mathrm{nM} \mathrm{OA}$ for $1 \mathrm{~h}$, when indicated. PP2A activity was determined by the malachite green assay. ${ }^{*} \mathrm{p}<0.05,{ }^{* * *} \mathrm{p}<0.001$ versus $\mathrm{pLTR} 2+$ HrasT $\# \mathrm{p}<0.05$ versus nontreated $\mathrm{C} 3 \mathrm{G} \Delta \mathrm{Cat}+\mathrm{HrasT}$; \#\#p $<0.01$ versus non-treated $\mathrm{C} 3 \mathrm{G}+$ HrasT. The histogram represents the media and s.d. of six independent experiments. Lower: Representative Western blot of the same immunoprecipitates used for the PP2A assays showing similar amounts of PP2A in all samples. Numbers indicate the samples order. (B) Lysates of the indicated clones, growing in $20 \%$ FBS, were subjected to immunoblotting with anti-phospho-PP2A (p-PP2A) antibodies. After stripping, the blot was incubated with anti-PP2A antibodies. The graphic corresponds to two different experiments and represents the ratio phospho-PP2A/PP2A in relative units. ${ }^{*} \mathrm{p}<0.05,{ }^{*} \mathrm{p}<0.01$ versus $\mathrm{pLTR} 2+$ HrasT. (C) Immunoblots, with the indicated antibodies, of total cell lysates of same clones as in B treated or not with $2 \mathrm{nM} \mathrm{OA}$ (1h). HrasT: Hras ${ }^{\text {Lys12 }}$. The ratio p-PP2A/PP2A is indicated.

Fig. 4. C3G interacts and colocalizes with PP2A. (A) Cell lysates $(0.5 \mathrm{mg})$ of the indicated clones were immunoprecipitated with anti-PP2A antibodies and the presence of PP2A or C3G detected by immunoblotting. C3G and PP2A expression was also determined in the total cell lysates (TCL panels). (B) Cell lysates of transiently transfected NIH3T3 clones were immunoprecipitated with anti-C3G (H-300) antibody and the presence of PP2A or C3G detected by immunoblotting. The first four lanes (TCL) correspond to total cell lysates ( $20 \mu \mathrm{g})$. 
b: beads incubated with cell lysate. (C) Inmunofluorescences of permanently transfected NIH3T3 clones, overexpressing HrasT alone or in combination with C3G or C3G $\Delta$ Cat, with anti-C3G 1008 and anti-PP2A antibodies, where C3G is visualized with anti-rabbit-Cy3 (upper panels) and PP2A with anti-mouse FITC secondary antibodies (middle panels). The superposition of both signals is represented in the lower panels. Cells were grown in $20 \%$ FBS without treatment (-) or treated (+) with $1 \mu \mathrm{g} / \mathrm{ml}$ of cytochalasin D (CytD) for 20 minutes. HrasT: Hras ${ }^{\text {Lys12 }}$. The scale bars represent 50 and $100 \mu \mathrm{m}$.

Fig. 5. PP2A mediates C3G inhibitory effect on ERK phosphorylation. (A) C3G upregulates PP2A interaction with MEK and ERK. Cell lysates of the indicated clones were immunoprecipitated with anti-phospho-ERK1/2 antibodies (p-ERK) or anti-phospho-MEK1/2 antibodies (p-MEK) and PP2A detected by immunoblotting. PP2A, p-ERK1/2, ERK1/2, C3G and $\mathrm{C} 3 \mathrm{G} \Delta \mathrm{Cat}$ expression were detected in total cell lysates (TCL) with corresponding antibodies. (B) Immunoblottings of phospho-ERK1/2 (upper panel) in cell lysates of pLTR2+HrasT and $\mathrm{C} 3 \mathrm{G}+$ HrasT clones treated with okadaic acid (OA) as indicated. After stripping, phospho-ERK blot was incubated with anti-phospho-PP2A antibodies (middle panel) and, after a second stripping, with anti-ERK antibodies (lower panel). (C) Cell lysates of the indicated clones were immunoprecipitated with anti-C3G (H-300) antibodies and the presence of Ksr-1 and PP2A detected by immunoblotting with specific antibodies. Lower panels: Ksr-1 and $\mathrm{C} 3 \mathrm{G} / \mathrm{C} 3 \mathrm{G} \Delta \mathrm{Cat}$ expression in the TCL. HrasT: Hras ${ }^{\text {Lys12 }}$. b: beads incubated with cell lysate.

Fig. 6. C3G interacts with actin in vivo and in vitro. (A) $\mathrm{C} 3 \mathrm{G}$ colocalizes with actin at the subcortical cytoskeleton. Inmunofluorescences performed in stably transfected NIH3T3 cells with pLTR2+HrasT, C3G+HrasT and $\mathrm{C} 3 \mathrm{G} \Delta \mathrm{Cat}+$ HrasT in which $\mathrm{C} 3 \mathrm{G}$ is visualized by 
incubation with antibody anti-C3G \#1008 followed by incubation with Cy3, F-actin is stained for Oregon-Green 514 Phalloidin, and merged panels are in lower position. Cells were grown in $20 \%$ FBS without treatment (-) or treated (+) with $1 \mu \mathrm{g} / \mathrm{ml}$ of cytochalasin D for 20 minutes. (B) $\mathrm{C} 3 \mathrm{G}$, but not $\mathrm{C} 3 \mathrm{G} \Delta$ Cat localizes at the Golgi. Same NIH3T3 stably transfected clones were stained for $\mathrm{C} 3 \mathrm{G} \# 1008$ and $\mathrm{Cy} 3$ and the yuxtanuclear region of Golgi apparatus stained for GM130 (FITC). The merged images are shown in the lower panels. The scale bar represents $100 \mu \mathrm{m}$. (C) Cell lysates of the same NIH3T3 stable transfectants were subjected to immunoprecipitation with anti-C3G (H-300) antibodies and C3G-actin complexes visualized by immunoblotting with anti-C3G and anti-actin (c-11) antibodies. The specificity of actin signal was demonstrated by stripping and reblotting with anti-actin antibodies blocked with the control peptide $(\mathrm{CP})$. In parallel, expression levels of $\mathrm{C} 3 \mathrm{G} / \mathrm{C} 3 \mathrm{G} \Delta \mathrm{Cat}$ and actin were analyzed by immunoblotting using $20 \mu \mathrm{g}$ of total cell lysates (TCL) and corresponding antibodies (lower panels). HrasT: $\operatorname{Hras}^{\text {Lys12 }}$. b: beads incubated with cell lysate.

\section{Fig. 7. C3G and C3GACat inhibition of ERK1/2 phosphorylation requires an intact actin} cytoskeleton. Lysates of NIH3T3 clones permanently transfected with pLTR2+HrasT, $\mathrm{C} 3 \mathrm{G}+\mathrm{HrasT}$ or $\mathrm{C} 3 \mathrm{G} \Delta \mathrm{Cat}+\mathrm{Hras} \mathrm{T}$ were treated as indicated and the levels of phospho-ERK1/2 (p-ERK1/2) determined by immunoblotting with specific antibodies. Blot was stripped and incubated with anti-ERK antibodies as loading control. CytD: cytochalasin D; HrasT: $\operatorname{Hras}^{\text {Lys12. }}$. 


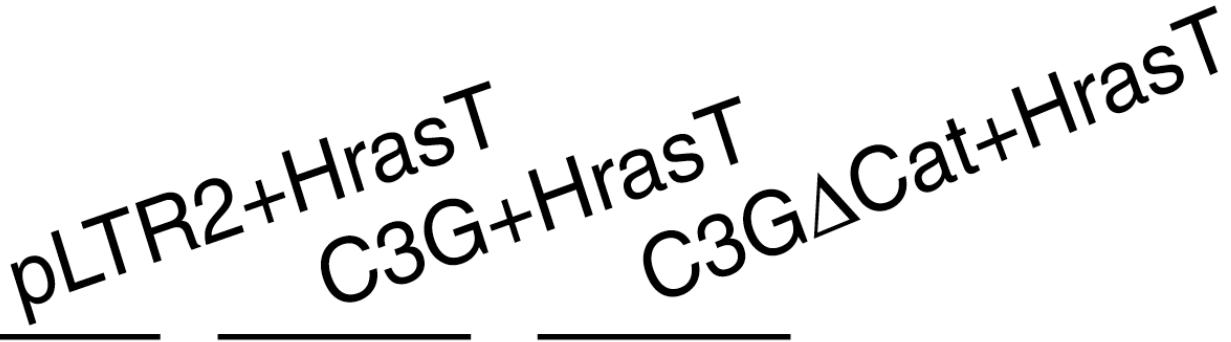

$$
\begin{aligned}
& \text { FBS }-++-++-+ \\
& \mathrm{PD}-+-{ }^{-}-{ }^{+}-\mathrm{b} \\
& \text { p-ERK2 }
\end{aligned}
$$
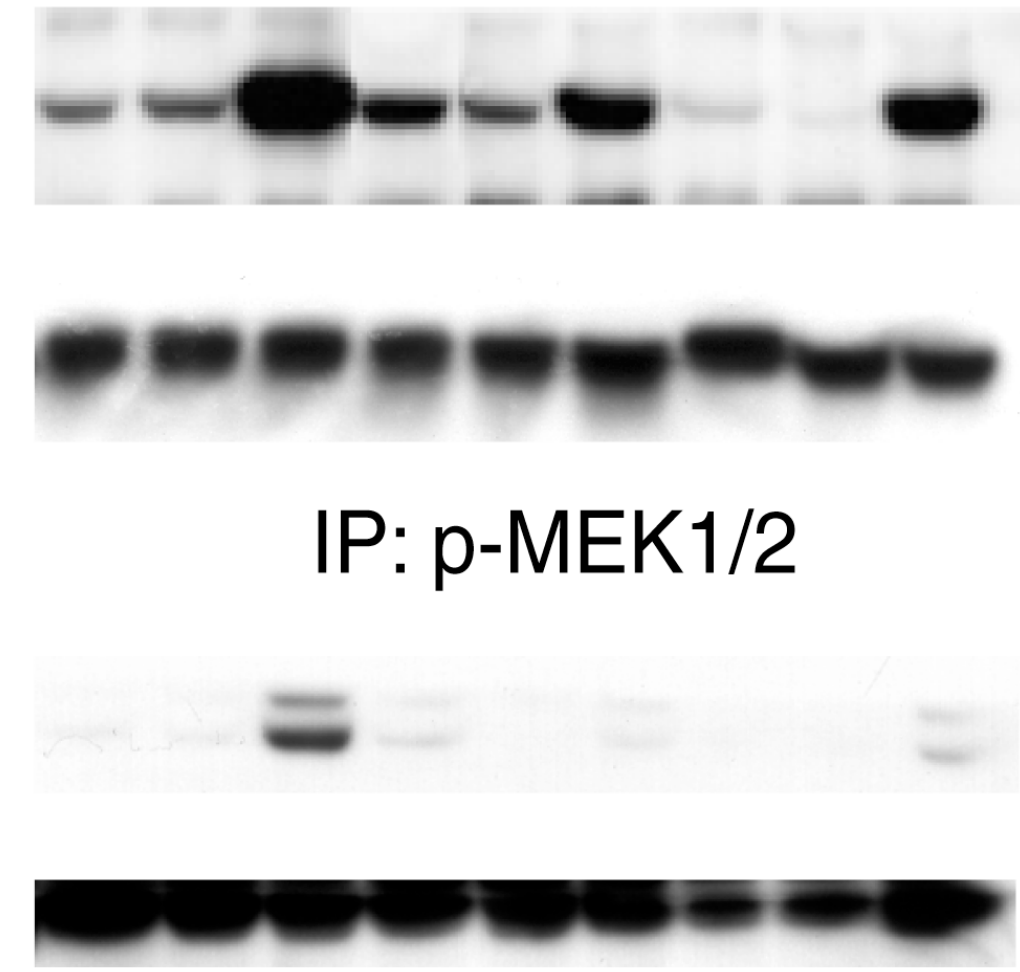

\section{Figure 1}


A
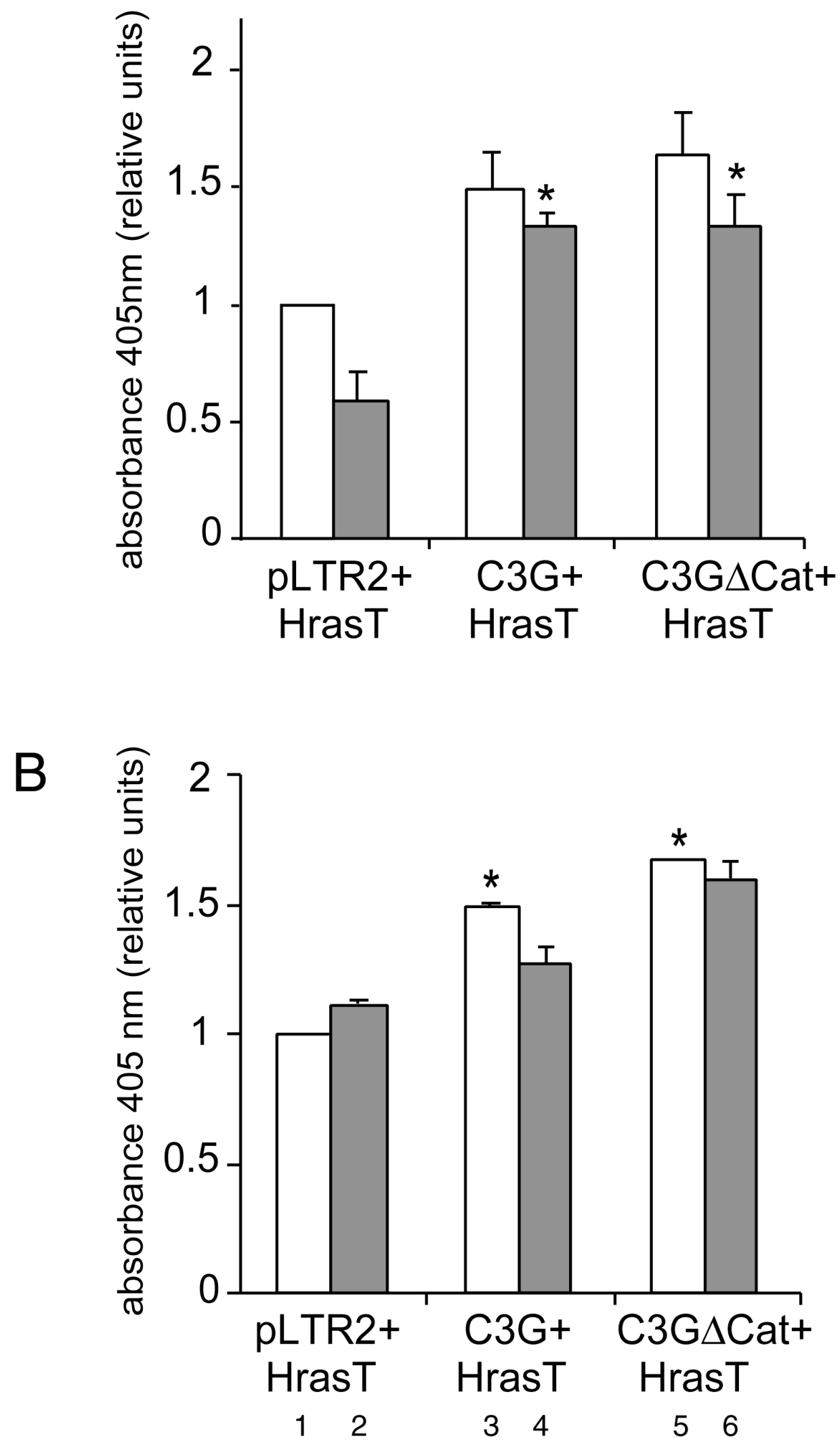

ERK $1 / 2$

$\begin{array}{llllll}1 & 2 & 3 & 4 & 5 & 6\end{array}$

Figure 2 


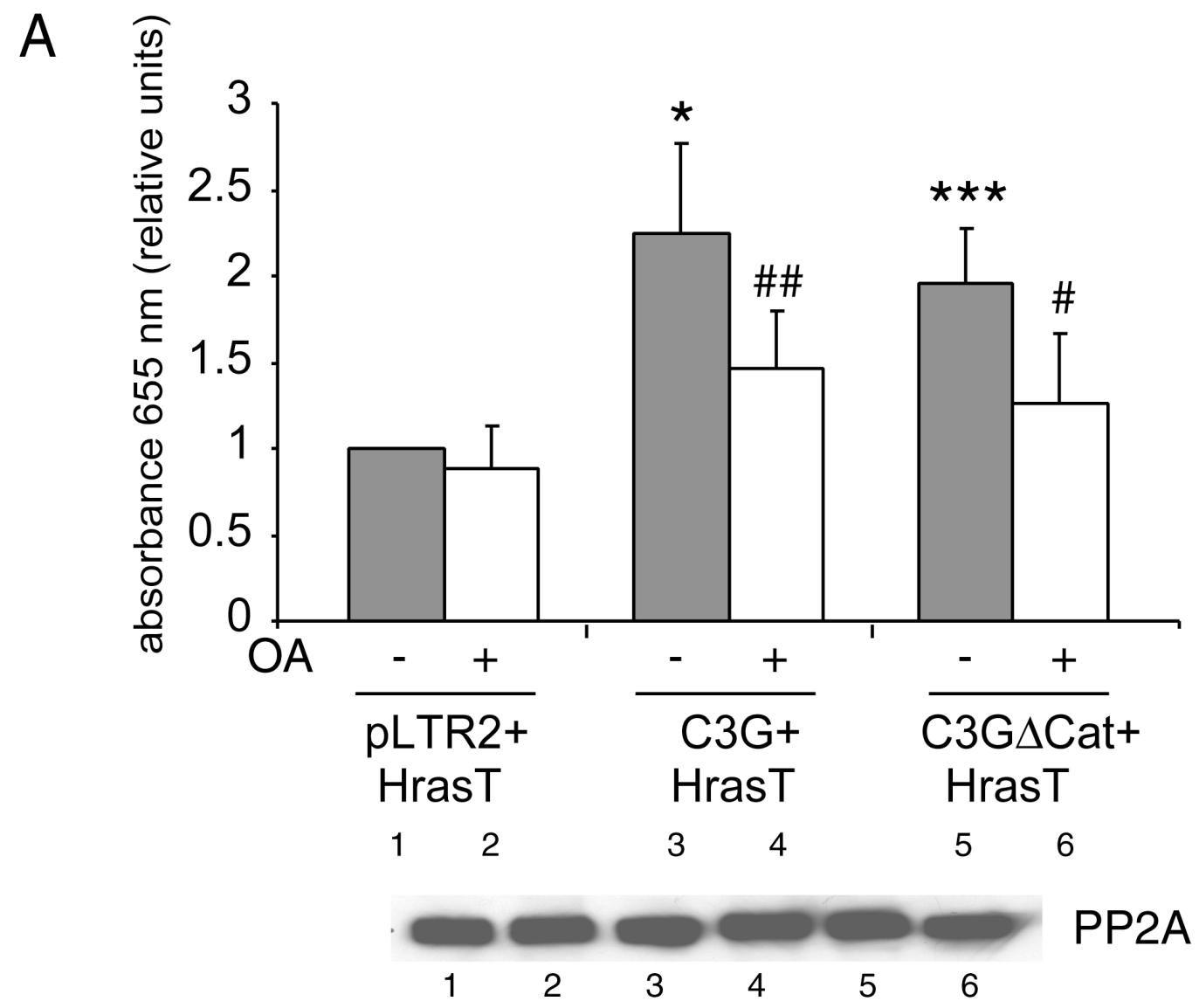

B

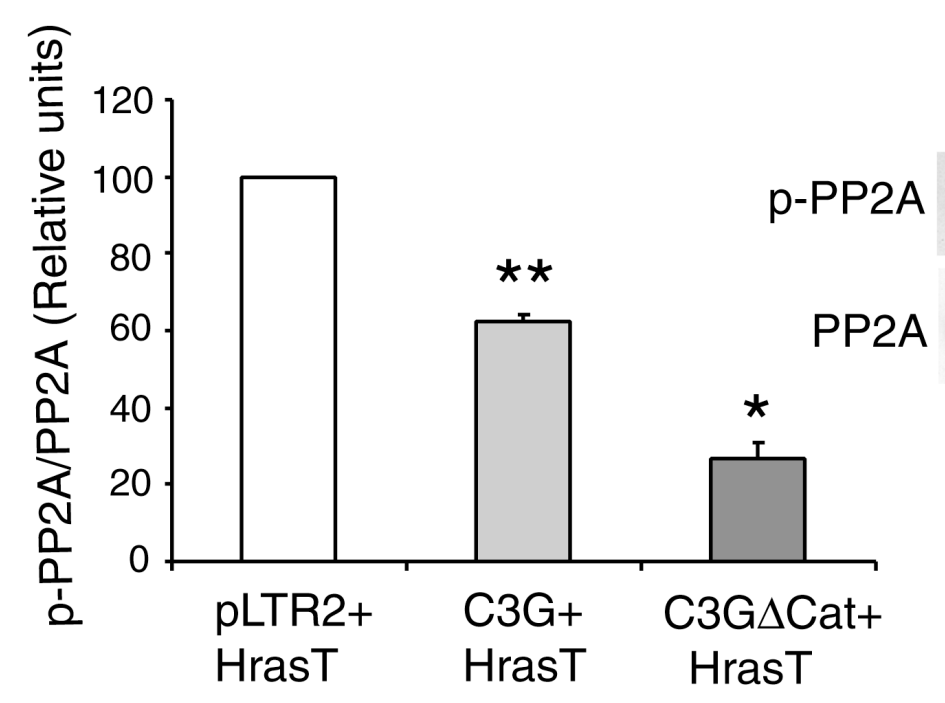

C

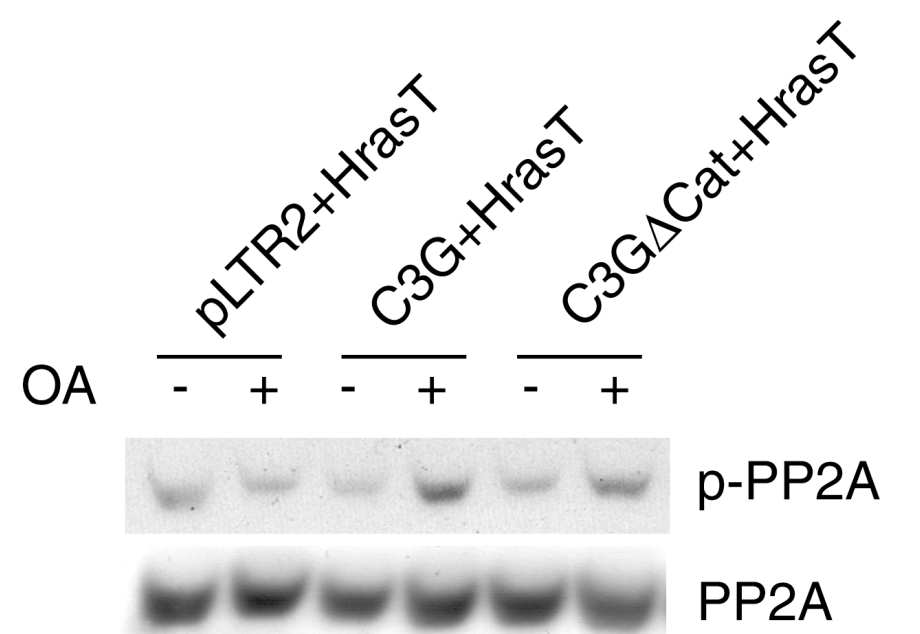

Figure 3 
A

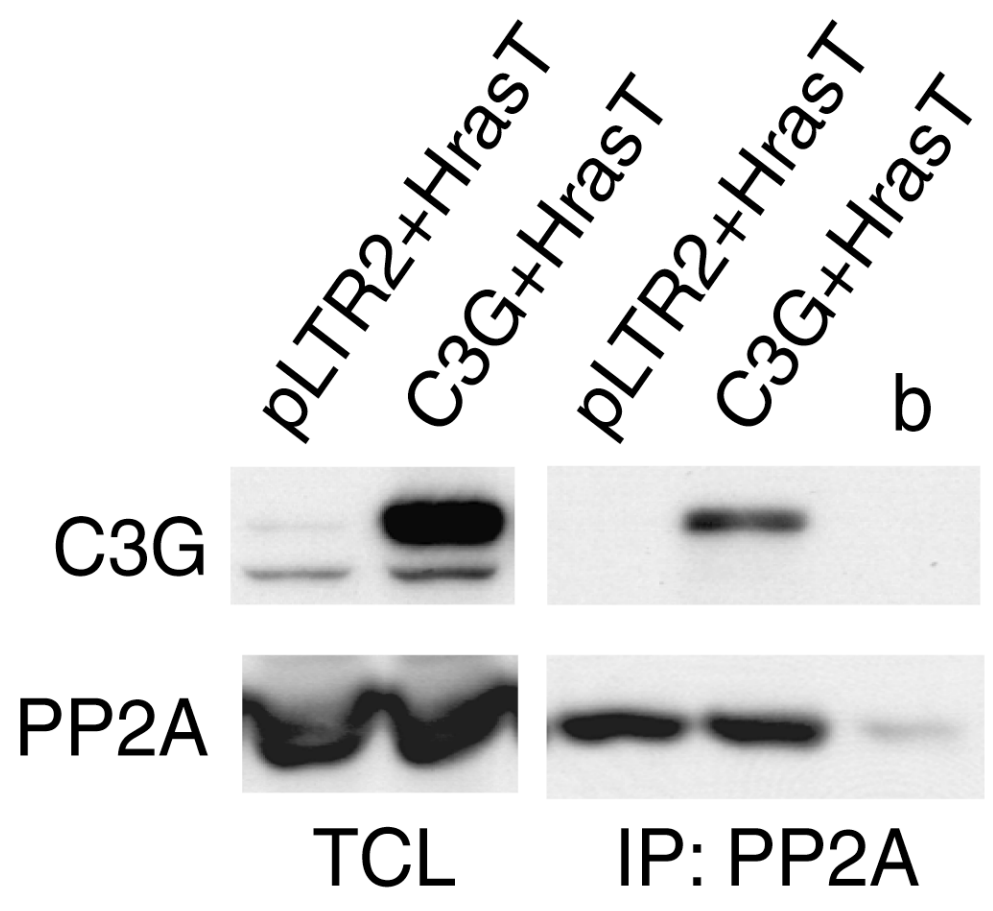

B

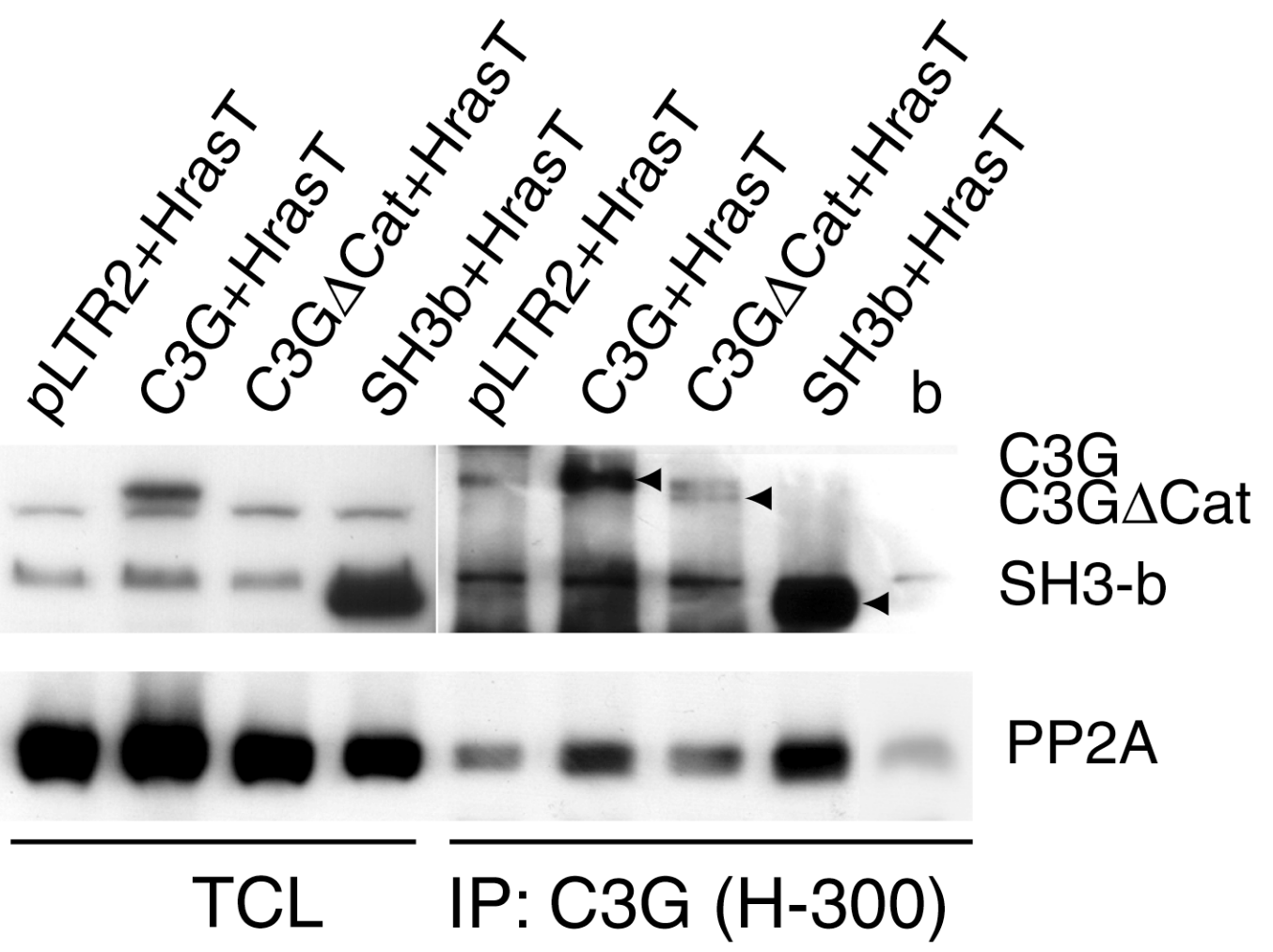

Figure 4 
C

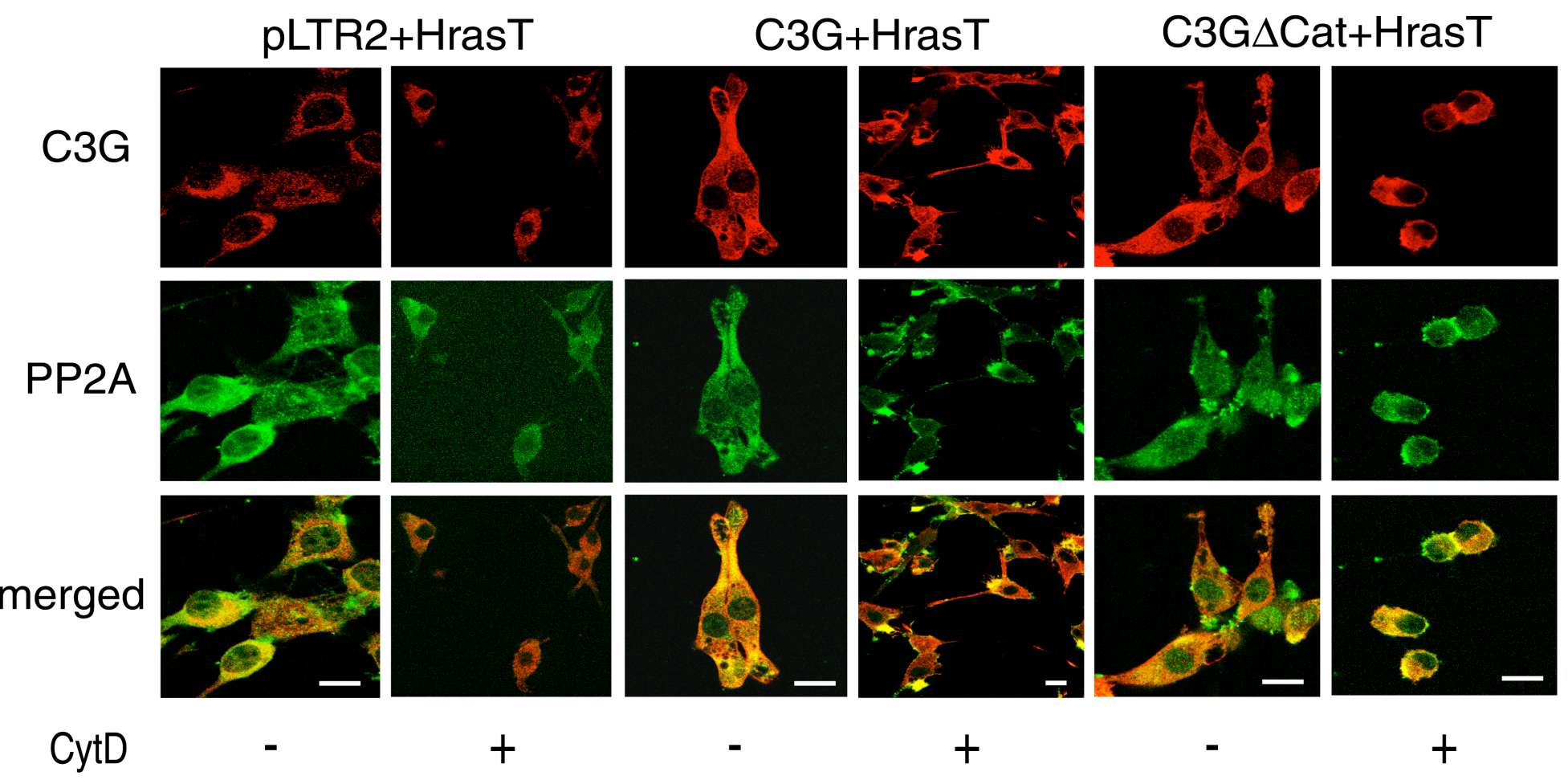

Figure 4 
A

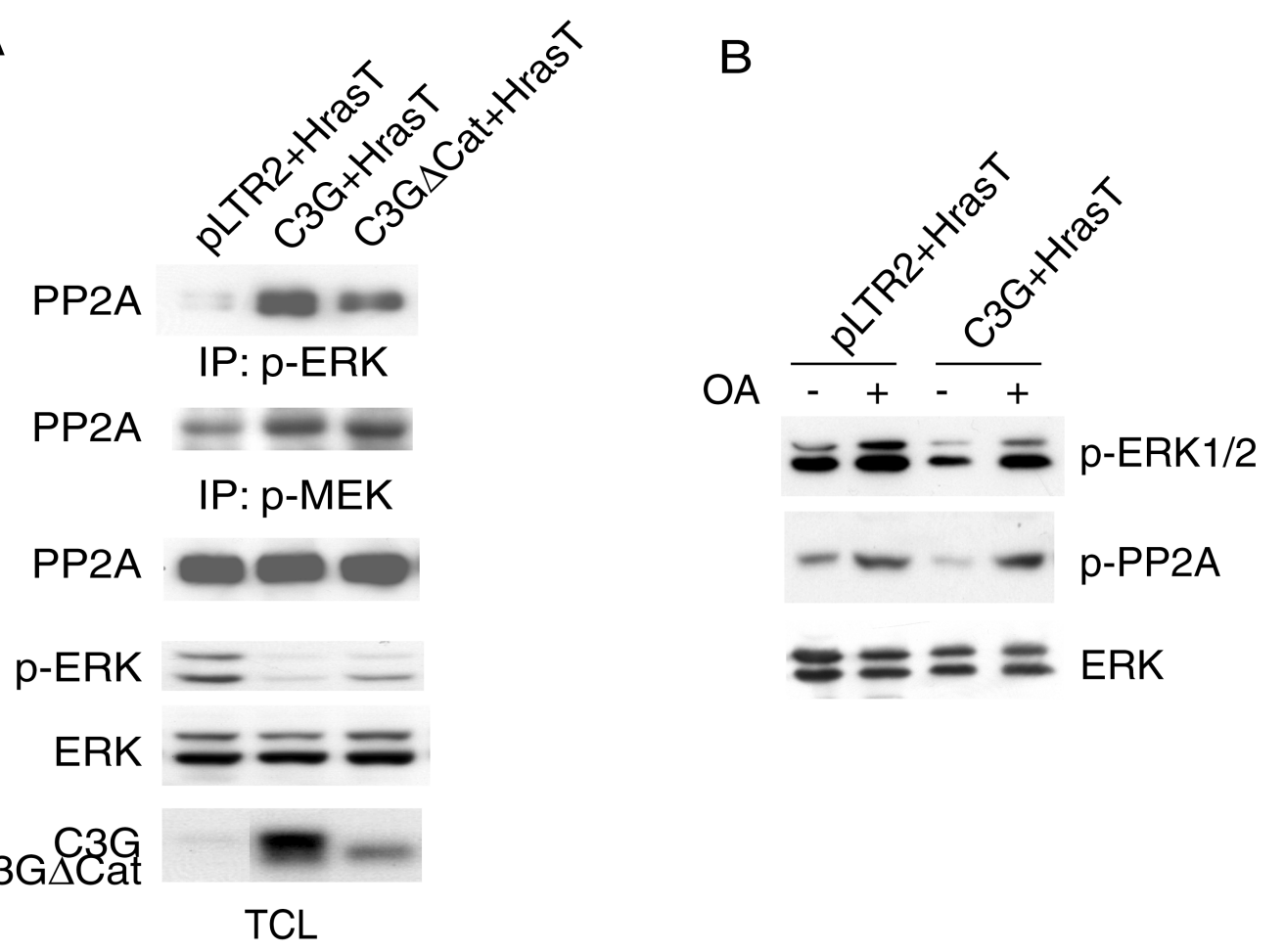

C

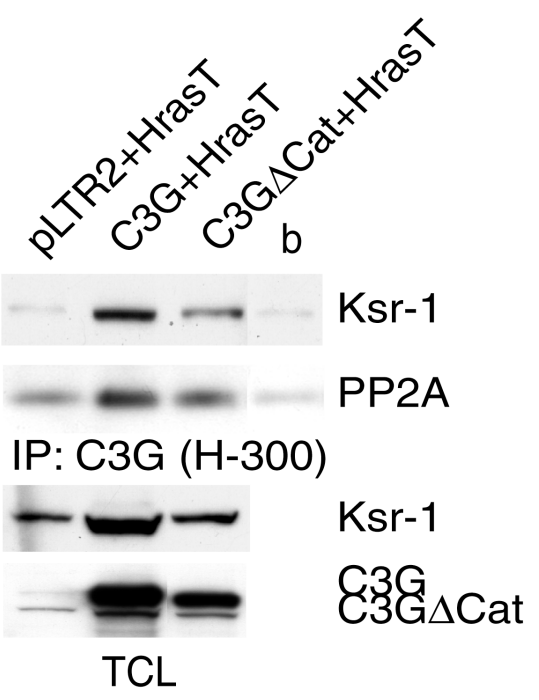

Figure 5 


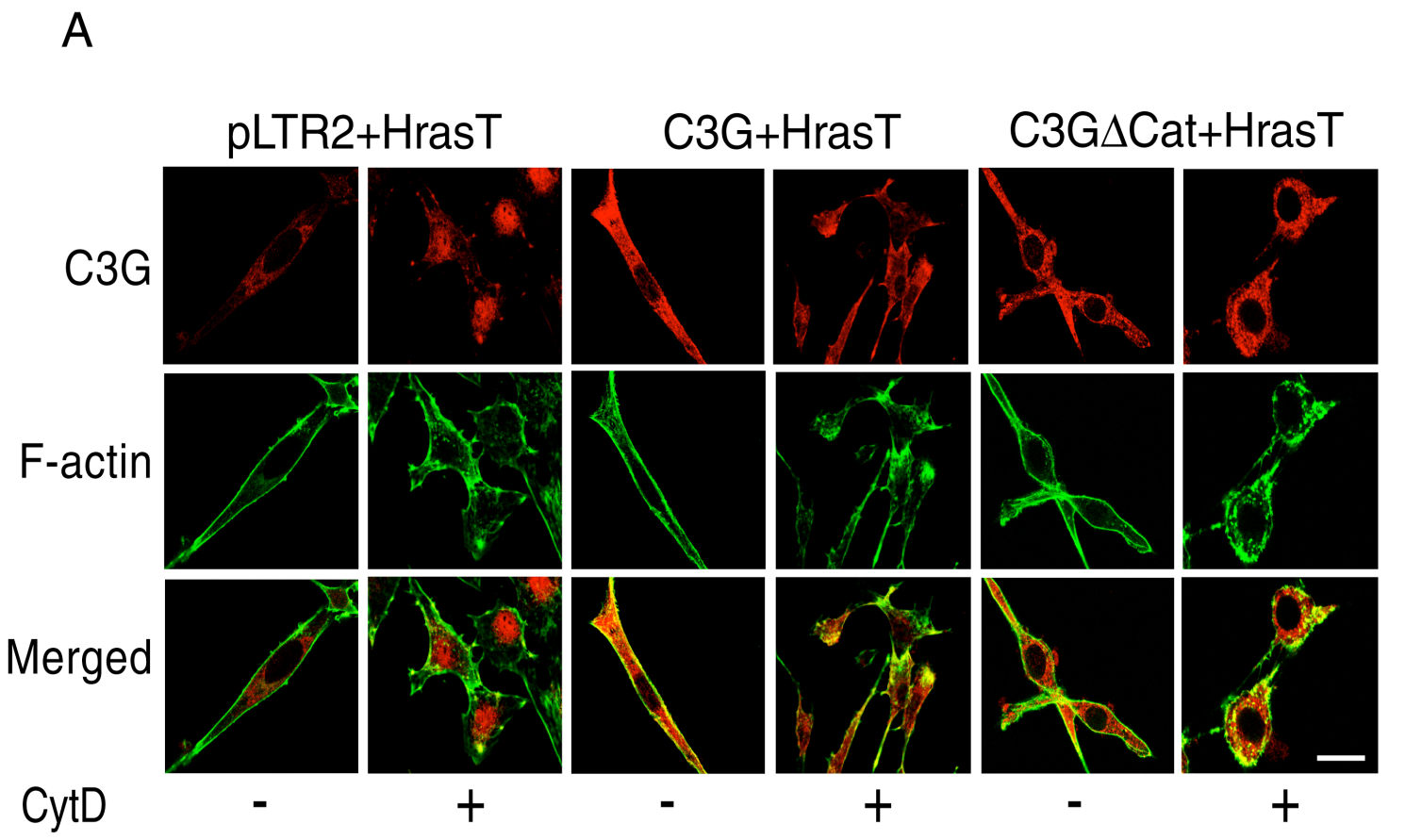

B

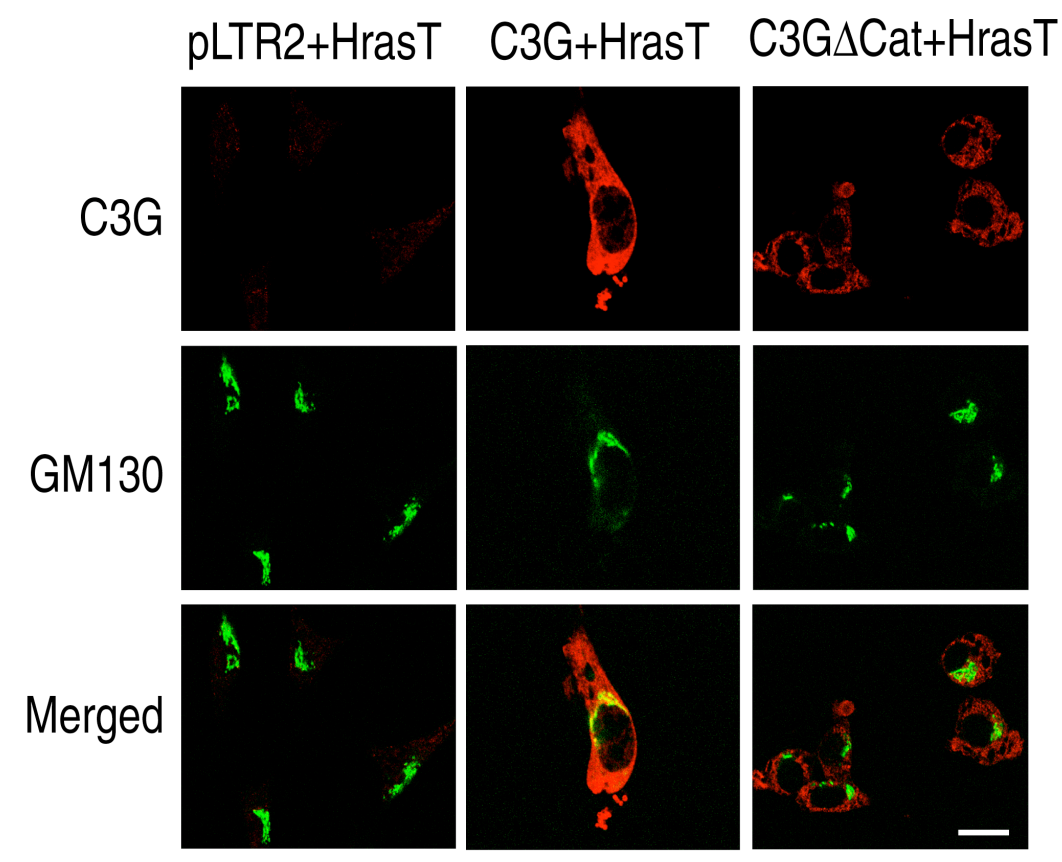

Figure 6 
C

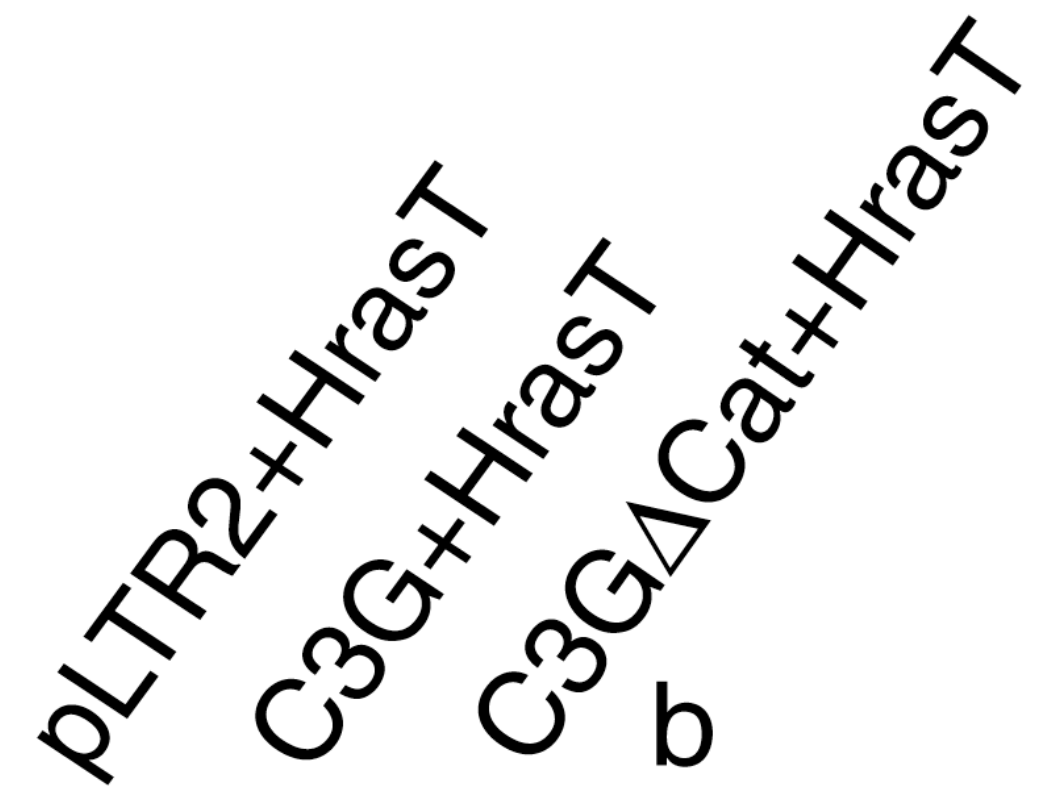

\section{actin}

actin

$+\mathrm{CP}$

C3G $\Delta$ Cat $\rightarrow$

IP: C3G (H-300)

$\underset{\mathrm{C} 3 \mathrm{G} \Delta \mathrm{CaG} \rightarrow}{\rightarrow}$

actin

Figure 6 


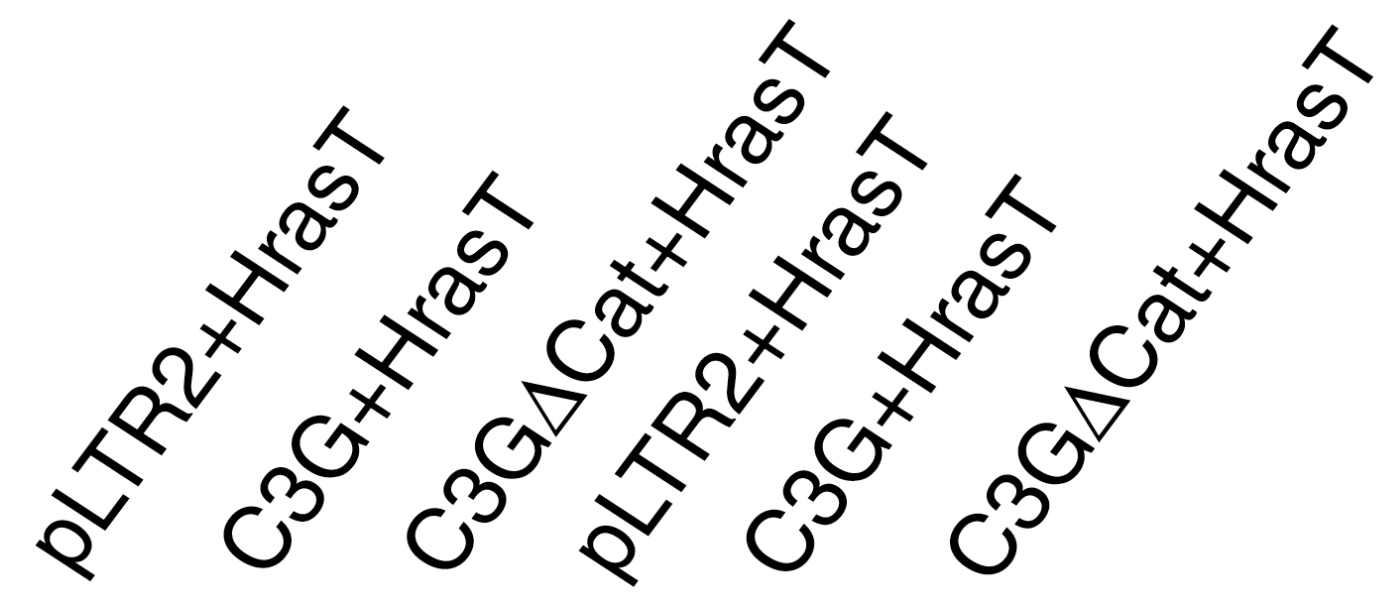

$\mathrm{p}-\mathrm{ERK} 1 / 2$

\section{ERK}

CytD - $-\quad-\quad+\quad+\quad+$

\section{Figure 7}

